\title{
Assessing a low-cost methane sensor quantification system for use in complex rural and urban environments
}

\author{
Ashley Collier-Oxandale ${ }^{1}$, Joanna Gordon Casey $^{2}$, Ricardo Piedrahita $^{3}$, John Ortega ${ }^{4}$, Hannah Halliday $^{5}$, \\ Jill Johnston ${ }^{6}$, and Michael P. Hannigan ${ }^{2}$ \\ ${ }^{1}$ Department of Environmental Engineering, University of Colorado Boulder, Boulder, CO 80309, USA \\ ${ }^{2}$ Department of Mechanical Engineering, University of Colorado Boulder, Boulder, CO 80309, USA \\ ${ }^{3}$ Berkeley Air Monitoring Group, Boulder, CO 80302, USA \\ ${ }^{4}$ National Center for Atmospheric Research, Boulder, CO 80301, USA \\ ${ }^{5}$ NASA Langley Research Center, Hampton, VA 23666, USA \\ ${ }^{6}$ Department of Preventive Medicine, University of Southern California, Los Angeles, CA 90089, USA
}

Correspondence: Ashley Collier-Oxandale (ashley.collier@colorado.edu)

Received: 22 November 2017 - Discussion started: 12 January 2018

Revised: 9 May 2018 - Accepted: 15 May 2018 - Published: 20 June 2018

\begin{abstract}
Low-cost sensors have the potential to facilitate the exploration of air quality issues on new temporal and spatial scales. Here we evaluate a low-cost sensor quantification system for methane through its use in two different deployments. The first was a 1-month deployment along the Colorado Front Range and included sites near active oil and gas operations in the Denver-Julesburg basin. The second deployment was in an urban Los Angeles neighborhood, subject to complex mixtures of air pollution sources including oil operations. Given its role as a potent greenhouse gas, new low-cost methods for detecting and monitoring methane may aid in protecting human and environmental health. In this paper, we assess a number of linear calibration models used to convert raw sensor signals into ppm concentration values. We also examine different choices that can be made during calibration and data processing and explore cross sensitivities that impact this sensor type. The results illustrate the accuracy of the Figaro TGS 2600 sensor when methane is quantified from raw signals using the techniques described. The results also demonstrate the value of these tools for examining air quality trends and events on small spatial and temporal scales as well as their ability to characterize an area - highlighting their potential to provide preliminary data that can inform more targeted measurements or supplement existing monitoring networks.
\end{abstract}

\section{Introduction}

\subsection{Background and motivation}

Given both the direct impacts on climate change and indirect impacts on human health, it is important to study increased atmospheric methane on varied temporal and spatial scales. Methane is an important greenhouse gas with $28 \times$ the global warming potential of $\mathrm{CO}_{2}$ over a 100 -year lifetime (IPCC, 2015); moreover, the majority of methane emissions result from human activity (US EPA, 2017). Researchers using ice core samples to measure historic methane levels found relatively stable atmospheric concentrations of approximately 0.695 ppm from $1000 \mathrm{AD}$ until the Industrial Revolution (Etheridge et al., 1988), after which methane concentrations have grown to a present-day global average of $1.851 \mathrm{ppm}$ (NOAA, 2017). This increased atmospheric methane not only intensifies climate change but also contributes to higher ground-level ozone - a public health risk (Fiore, 2008). Multiple modeling studies have revealed the benefits of reducing methane emissions, which include decreased premature mortality from respiratory illness caused by ozone (West et al., 2006; Fang et al., 2013). A better understanding of emissions and sources could help in the effort to reduce atmospheric methane.

In 2015, production, storage, processing, and distribution of natural gas and petroleum were responsible for approximately one-third of methane emissions in the US (US EPA, 
2017). While all of the leaks along this chain, from production to distribution, contribute to climate change, vented and fugitive emissions of methane that occur at oil and gas production sites may raise concerns for nearby communities due to potential co-emission of hazardous BTEX (benzene, toluene, ethylbenzene, and xylene) compounds (Adgate et al., 2014; Helmig et al., 2014; Moore et al., 2014). Recent studies also suggest that methane emissions from the oil and gas sector are underestimated in current inventories (Miller et al., 2013; Wilcox et al., 2014; Zavala-araiza et al., 2015; Petron et al., 2014; Subramanian et al., 2015). Miller and colleagues found that methane emissions in US EPA inventories may be underestimated by a factor of 1.5 (Miller et al., 2013). It has been suggested that these discrepancies between measured methane and source-based inventory estimates may be explained by "super-emitters" - a small percentage of sites or equipment that contribute a large portion of the emissions (Wilcox et al., 2014; Petron et al., 2014). For example, a study in the Barnett Shale region found that at any given time, $2 \%$ of facilities accounted for half of methane emissions and that these sites vary spatiotemporally (Zavala-araiza et al., 2015). As described in a recent review, smart-sensing systems designed to detect leaks and alert operators at the well pad level may aid in identifying these events as they occur (Allen, 2014), speaking to the need for tools that can feasibly achieve useful spatial and temporal resolution for monitoring at the local or facility level.

\subsection{Low-cost sensors for air quality monitoring}

\subsubsection{A place for sensors}

Typically monitoring methods and technologies are driven by the research question of interest and available resources. For example, the National Oceanic and Atmospheric Administration (NOAA) has maintained a global monitoring network for methane for upwards of 30 years to study long-term atmospheric trends, seasonal cycles, and its global distribution (NOAA, 2017). Monitoring networks can also be built on smaller scales to study methane fluxes at the regional or city level; the Megacities Carbon Project is currently undertaking this work in Southern California, as is the INFLUX project in Indianapolis (Wong et al., 2015; Davis et al., 2017). Remote sensing provides a global picture and, given the spatial coverage, these data can highlight hotspots at the regional scale (Kort et al., 2014). However, interferences and satellite trajectories prevent truly continuous data collection for any single location. Aircraft campaigns and mobile monitoring using vehicles equipped with gas analyzers both allow for horizontally and vertically resolved spatial coverage at the neighborhood or facility level. Additionally, these methods facilitate the collection of high-quality data with precise instrumentation (Yacovitch et al., 2015; Karion et al., 2013). However, aircraft data typically represent a "moment in time" and changing meteorological conditions often limit the ability to repeat data collection. Ground-based mobile monitoring may be repeated more easily, but the data collected are often periodic in nature and intended for targeted studies. Currently the scientific and regulatory communities are limited in their capability to collect data continuously at the neighborhood or facility level. While it would be possible to site the same high-quality instruments utilized in global and regional monitoring networks at a local scale, this approach would be costly given the expense of the equipment, the siting requirements, and the expertise needed for operation.

Low-cost air quality sensing systems are well suited to fill this role by providing continuous measurements in highdensity networks at a local scale. Given their versatility and capacity to provide data of high spatial and temporal resolution, these systems could augment regulatory monitoring systems, aid in compliance monitoring (e.g., leak detection), or enable the public to formulate local strategies to reduce their exposure (Snyder et al., 2013). These systems are relatively easy to deploy and operate in nearly any type of location due to their size, low power requirements, and automated electronic data collection. These characteristics also make them more accessible for community-engaged research applications than conventional methods (Shamasunder et al., 2017). For example, these systems could support a community collecting preliminary data, in partnership with researchers or local regulatory agencies, that could be evaluated for "hotspots" or correlated with community members' experiences (e.g., odors or health symptoms) - providing more information to support better understandings of complex air quality issues.

\subsubsection{Previous sensor research}

Several studies have demonstrated the ability of low-cost sensors to measure pollutants of interest at ambient levels. For example, $\mathrm{CO}, \mathrm{NO}$, and $\mathrm{NO}_{2}$ have been measured in an urban sensor network with additional analysis demonstrating the ability to differentiate local emissions from regional trends (Mead et al., 2013; Heimann et al., 2015). In another example, researchers demonstrated the feasibility of collecting personal $\mathrm{CO}, \mathrm{NO}_{2}, \mathrm{O}_{3}$, and $\mathrm{CO}_{2}$ exposure data with uncertainty estimations using a portable, wearable system (Piedrahita et al., 2014). Several studies have also made use of sensors to study the spatial variability of $\mathrm{O}_{3}$ on various scales (Sadighi et al., 2018; Cheadle et al., 2017; Moltchanov et al., 2015). Connected to this effort on sensor applications, there has been much work evaluating the performance of individual sensors (Masson et al., 2015a, b; Spinelle et al., 2015, 2017; Lewis at al., 2016) and demonstrating the performance of different calibration approaches (Zimmerman et al., 2018; Kim et al., 2018; Cross et al., 2017).

While many projects utilize sensors capable of detecting criteria pollutants, advances in the development of metaloxide semiconductor (MOx) sensors have led to sensors ca- 
pable of detecting methane in settings closer to ambient environmental conditions (Quaranta et al., 1999; Biaggi-Labiosa, 2012). Eugster and Kling (2012) demonstrated the ability of the Figaro TGS 2600 sensor to resolve diurnal methane fluctuations in a remote area of Alaska. A similar sensor, the Figaro TGS 2611-E00, was found to have an accuracy of $\pm 1.7 \mathrm{ppm}$ in a laboratory setting for minute-averaged data, suggesting its suitability for detecting substantial methane leaks (Van den Bossche et al., 2017). These and similar metal-oxide volatile organic compound (VOC) sensors have also been utilized in other applications such as odor detection at landfills and electronic noses (Penza et al., 2015; Zhang et al., 2008).

This paper describes a methodology for collecting and quantifying data using Figaro TGS 2600 MOx sensors to examine ambient trends and methane enhancements on small spatial and temporal scales. Data from two field deployments are used to discuss the different considerations for calibrating and deploying these sensors. The first dataset was collected in Colorado during the FRAPPE/DISCOVER-AQ monitoring campaigns in the summer of 2014 (Pfister et al., 2017). This deployment primarily measured rural and semirural areas along the Front Range north of Denver; important sources of methane in the area include oil and gas development and agriculture/ranching. The second dataset was collected in California near downtown Los Angeles in the late summerearly fall of 2016 as part of a community-based research project. This deployment was in a mainly urban area with high-density housing near two major roadways and urban oil extraction. With this work, we build on the previous study by Eugster and Kling (2012) by demonstrating the use of these sensors in more complex environments where they are likely subject to a greater number and variety of local and regional influences. We (1) demonstrate methods for sensor calibration and validation of the Figaro TGS 2600 MOx sensors using field co-locations, (2) examine different options and issues that arise in the calibration process, and (3) explore the potential for the data from these sensors to offer unique information. This paper is intended to explore ways of adapting this system to fit the needs and logistical constraints of different investigations in order to provide useful and relevant methane estimations.

\section{Methods}

\subsection{Instrumentation - low-cost sensor systems}

In both deployments, embedded sensor systems termed UPods and Y-Pods (subsequent iterations of an open-source platform) were used for data acquisition (Mobile Sensing Technology, 2017). The main differences between the two versions were in the circuit board design and the programming, which was altered to improve reliability. Each U-Pod and Y-Pod (pod) was outfitted with multiple gas-phase and environmental sensors, listed in Table 1. The two Figaro VOC sensors were originally developed for monitoring in industrial applications where much higher pollutant concentrations are expected compared to ambient environmental monitoring. The following analysis will primarily utilize signals from one of these VOC sensors - the Figaro TGS 2600 MOx sensor. This is the same sensor used by Eugster and Kling in Alaska (2012), deployed here in environments characterized by complex mixtures including methane emissions and associated confounding gas species.

These embedded sensor systems are housed in small weather-proof plastic cases (approximately $20 \mathrm{~cm} \times 25 \mathrm{~cm} \times 10 \mathrm{~cm}$ ) with fans to pull ambient air through the enclosure and across the sensor surfaces resulting in multiple air exchanges occurring each minute. The systems in these weatherproof cases can be placed outdoors for long periods of time. They are powered using $12 \mathrm{~V}$ AC/DC adapters plugged into wall power, but can use car batteries and/or solar power in remote locations. All data are logged to an onboard micro-SD card. As configured, these pods draw roughly $11 \mathrm{~W}$. These systems have been used in several other indoor and outdoor air quality studies (Casey et al., 2018; Sadighi et al., 2018; Cheadle et al., 2017). Figure 1 includes a labeled photo of a Y-Pod interior and a photo of two Y-Pods deployed.

\subsection{Deployment overview}

Regulatory monitors have strict siting guidelines; however, no such constraints exist for low-cost sensor systems. Once a site is selected, pod placement is chosen based on feasibility, access to air flow, and avoiding potential obstructions as much as possible to obtain samples that are representative of the area. As selecting sampling locations and setting up pods is typically a joint effort with community partners, different sites often require different approaches. For example, pods are typically placed on the roof of multi-story buildings, while we may place the pod on the edge of a first story roof or a fence of a single-family home. Additional considerations include access to power, whether the instrument is obstructing a walkway or driveway, and safety of the residents. In both deployments discussed in this paper, site selection was guided by the research goals and access to general air flow while also considering the preferences of the owner, tenants, or site manager.

In Colorado, the pods were used during the 2014 FRAPPE/DISCOVER-AQ campaign with the aim of characterizing small-scale spatial variability of pollutants. This deployment lasted roughly 1 month. The deployment of the pods was centered on a main site for the FRAPPE/DISCOVER-AQ campaign, the Boulder Atmospheric Observatory (BAO) Tower in Erie, Colorado. Fourteen pods were placed in an approximately $10 \times 10 \mathrm{~km}$ grid. The remaining four pods were placed to the southwest and northeast of the grid to provide regional comparisons, with 
Table 1. U-Pod and Y-Pod sensor lists.

\begin{tabular}{lll}
\hline Sensor type & U-Pod & Y-Pod \\
\hline Temperature and RH & RHT03 (also known as DHT22) & Sensirion SHT2 \\
Temperature and pressure & 47 Bosh BMP085 & Bosh BMP180 \\
Carbon dioxide & ELT S-100 NDIR & ELT S-300 NDIR \\
Ozone & SGX Corporation MiCS-2611 & SGX Corporation MiCS-2611 \\
VOC sensor 1 & Figaro TGS 2600 MOx & Figaro TGS 2600 MOx \\
VOC sensor 2 & Figaro TGS 2602 MOx & Figaro TGS 2602 MOx \\
Additional optional & Alphasense B4 series & Alphasense B4 series \\
Sensors & $\left(\mathrm{CO}, \mathrm{NO}, \mathrm{NO}_{2}, \mathrm{O}_{3}, \mathrm{SO}_{2}\right)$, & $\left(\mathrm{CO}, \mathrm{NO}, \mathrm{NO}_{2}, \mathrm{O}_{3}, \mathrm{SO}_{2}\right)$, \\
& Baseline Mocon PID & Baseline Mocon $\mathrm{PID}^{\mathrm{M}}$ \\
\hline
\end{tabular}

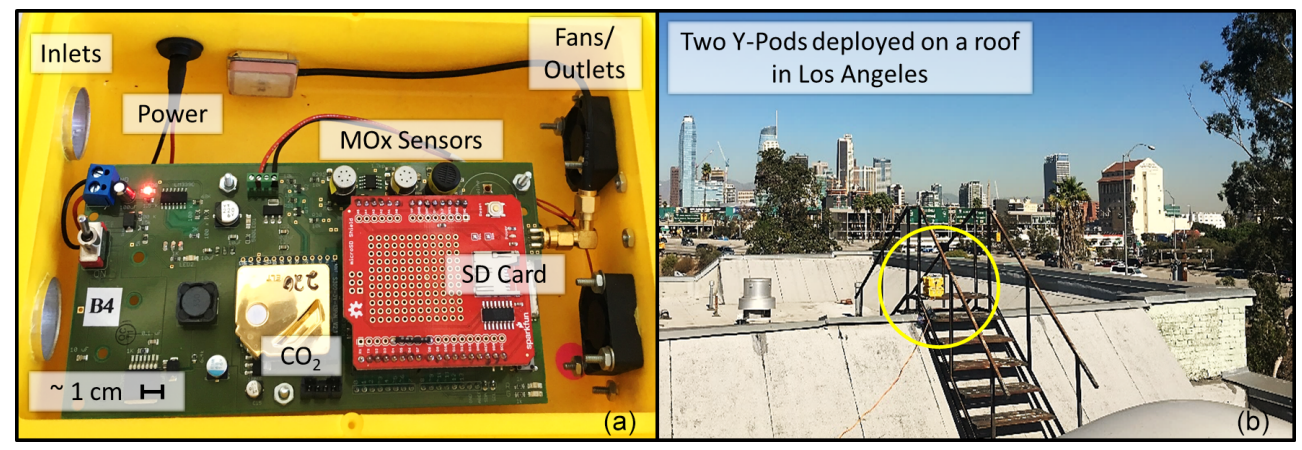

Figure 1. A labeled photo of a Y-Pod interior (a) and a photo of two Y-Pods deployed at a field site (b).

measurements taken at the Golden National Renewable Energy Laboratory (NREL), Frederick, and Platteville. All Colorado sites are shown in Fig. 2.

Shown in Fig. 2 are the boundaries of the Wattenberg Gas Field and all active and inactive wells. In general, oil and gas activity increases in density moving from the southwestern side of the deployment region to the northeastern side, with the Erie sites on the edge of the gas field. Note that the Golden site has no nearby oil and gas activity, while the Platteville site is surrounded by a high density of wells. The pods were sited in rural and suburban areas primarily at homes, schools, or in open spaces with two monitors sited at a water reclamation facility. Of the 18 monitors, data from 15 were included in the following analysis. Three monitors were excluded because of extended power failure, temperate or humidity sensor failure, or MOx VOC sensor malfunction. Some of the remaining 15 monitors experienced occasional power loss, but all necessary sensors operated continuously.

In Los Angeles, we partnered with two community-based organizations, Redeemer Community Partnership and Esperanza Community Housing, and deployed Y-Pods throughout a neighborhood south of downtown Los Angeles. This deployment lasted approximately 8 weeks. The community was specifically interested in deploying a monitoring network around an active oil extraction site. In this case, sites were selected at varying distances away from the drilling operation as well as varying distances from freeways, another potential source of pollutants (Fig. 3). Thirteen of the sites were within an approximately $5 \times 5 \mathrm{~km}$ grid, and two additional sites were located further to the northwest and northeast. These two additional sites were utilized because they allowed for continuous co-location with reference instruments for validation purposes. The deployment area in Los Angeles was primarily urban and suburban with high-density residential areas, some commercial and industrial land use, and much higher-density traffic than the Colorado deployment area.

Evaluating the performance of the Figaro TGS 2600 MOx sensor in the context of these two deployments provides the opportunity to better understand its strengths and limitations. In Colorado, the sensor network covered a larger area and we examined methane trends with respect to regional differences in potential sources. In Los Angeles, the sensor network covered a smaller area to examine local methane trends and to attempt to distinguish emissions from point sources. Another important distinction between the two locations is the nature of the oil and gas activity. In Colorado, the deployment was in the SW portion of the Denver-Julesburg Basin, which produces a mix of natural gas, condensate liquids, and crude oil (US EIA, 2016a). This area also includes the Wattenberg Field, which ranked in the top 10 for both oil- and gas-producing fields in 2013 (US EIA, 2015). In Los Angeles, oil and gas activity refers primarily to crude oil production. California is the fourth top-producing state for 

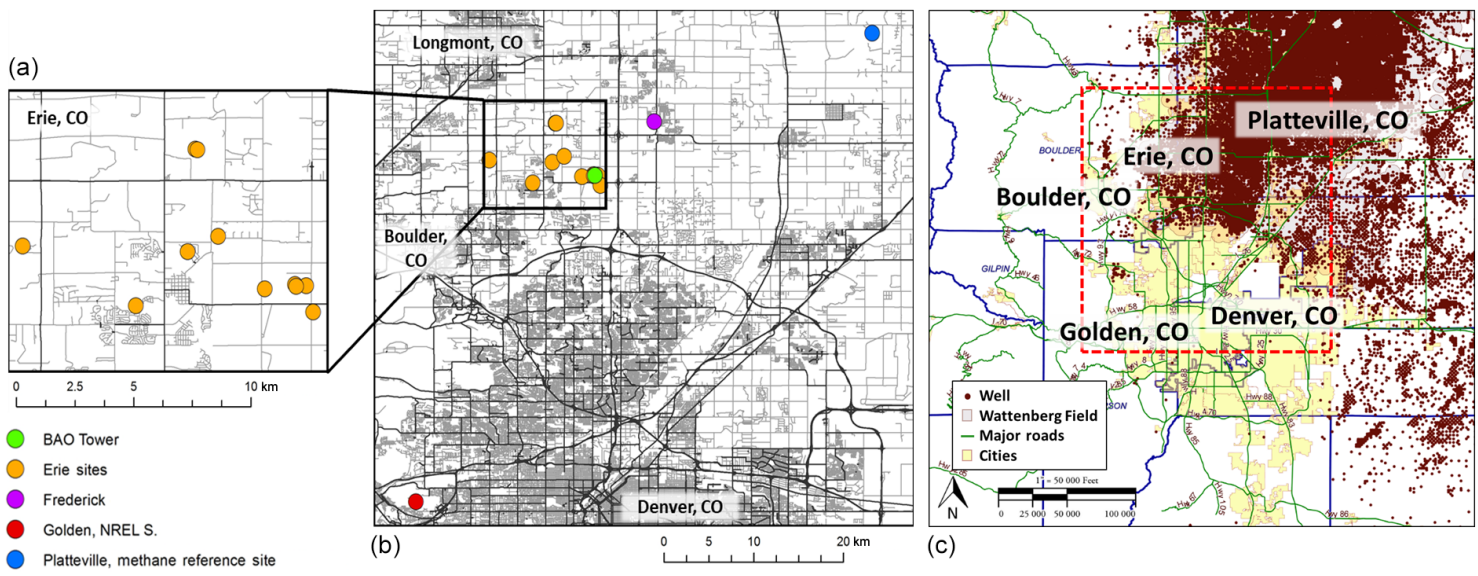

(c)

Figure 2. Maps of Colorado deployment area with every site displayed in panel (b) and the Erie sites displayed in panel (a). Panel (c) indicates active and inactive wells in the Wattenberg Gas Field along with major urban areas and counties; data are courtesy of the Colorado Oil and Gas Conservation Commissions (COGCC, 2017).

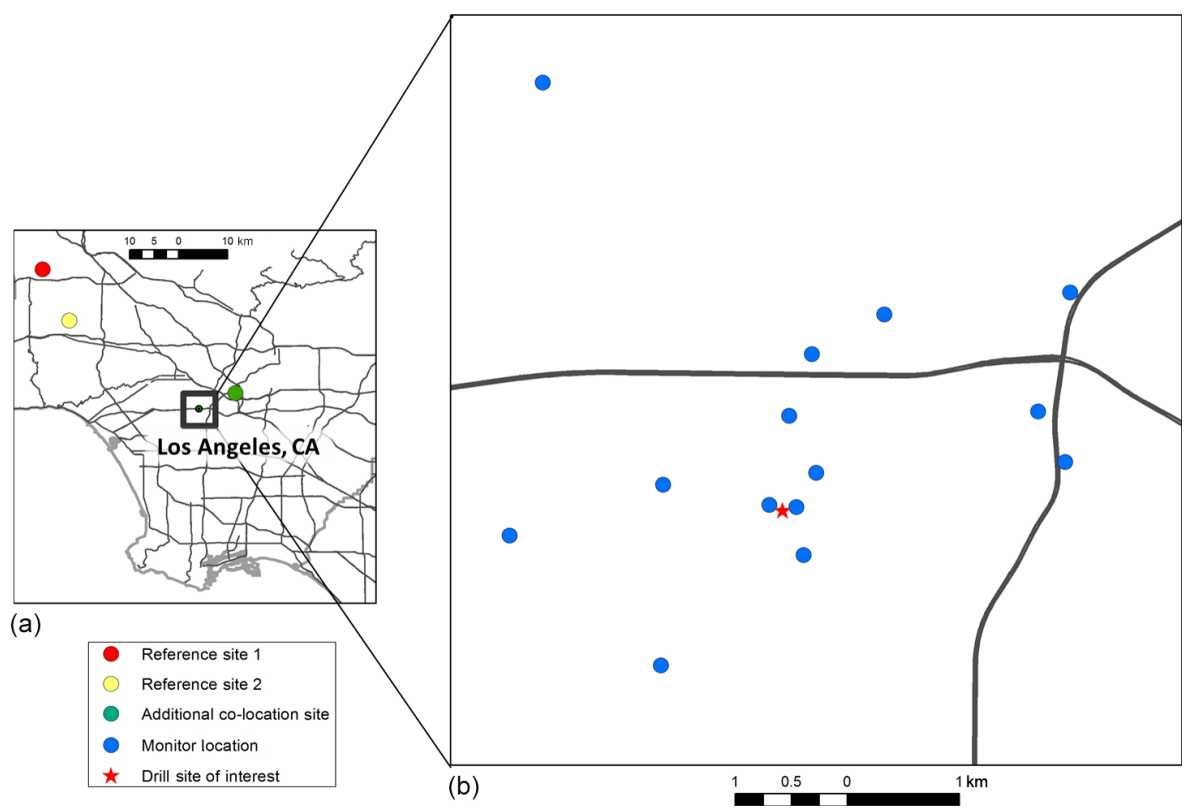

Figure 3. Map of Los Angeles deployment sites, showing (a) the deployment area and all sites where co-locations with reference monitors occurred and (b) the distribution of monitoring sites in relation to major roadways and the drill site of interest (note the monitor locations have been approximated to the center of their respective blocks to protect participant identities).

crude oil (US EIA 2016b), and Los Angeles County is home to more than 5000 active oil wells (Sadd and Shamasunder, 2015). In both cases we expect methane to be emitted or coemitted with other VOCs; we attempt to better understand local sources, methane may serve as a valuable indicator of emissions from these types of sites. The ratio of methane relative to other combustion products such as $\mathrm{CO}$ and $\mathrm{CO}_{2}$ will likely be higher from sites related to oil and gas activity than from other local sources such as traffic (Nam et al., 2004; Popa et al., 2014; Peischl et al., 2013). While the two deployment locations offer contrasting sampling environments, both locations offer complexity in terms of number and types of sources, geography, and typical atmospheric trends.

\subsection{Sensor signal processing}

The operating principle of MOx semiconductor sensors is based on a reducing gas changing the resistance of a semiconductor material in a simple resistance circuit (Sun et al., 2012). In clean air, the flow of current across the sensor surface is limited by donor electrons in the tin dioxide that are attracted to oxygen adsorbed to the sensor's surface. The flow 
of current increases when the target gas (e.g., methane) is present, thus reducing the amount of oxygen adsorbed to the sensor's surface (Figaro USA, Inc.). In other words, the resistance across the sensor decreases with increasing methane. In both the Y-Pods and U-Pods, the sensor voltage is continuously recorded to the SD card. Using Eq. (1), provided by the sensor manufacturer, we calculate the sensor resistance $\left(R_{\mathrm{S}}\right)$ at various concentrations (Figaro, 2005). In this equation $V_{\mathrm{c}}$ is the circuit voltage, $R_{\mathrm{L}}$ is the load resistance, and $V_{\text {out }}$ is the logged voltage. $R_{0}$ represents the resistance in clean air and the ratio of $R_{\mathrm{S}} / R_{0}$ is typically used in the analysis of MOx sensor data (Eugster and Kling, 2012; Piedrahita et al., 2014). Gas sensor signals, temperature, humidity, and pressure are recorded to the SD card approximately every 6-25 s (depending on a pod's programming). This frequent data acquisition allows for the use of minute-median data in calibration and analysis. Unless otherwise stated, this is the time resolution used in our analysis and shown in this paper.

$R_{\mathrm{S}}=\frac{V_{\mathrm{c}} \times R_{\mathrm{L}}}{V_{\text {out }}}-R_{\mathrm{L}}$

\subsection{Sensor calibration, validation, and analysis}

Field normalizations were used to generate calibration models for the sensors. Field normalization provides one approach to correcting for the cross sensitivities that lowcost sensors tend to exhibit with respect to temperature, humidity, and other trace gases (Spinelle et al., 2015, 2017; Sadighi et al., 2018; Masson 2015a, b; Wang et al., 2010). This method is implemented by co-locating low-cost sensor systems with high-quality reference instruments (typically regulatory-grade monitors) for a given period and then generating a calibration model using an approach such as linear regression. These calibration models predict the methane concentration (in ppm) based on the sensor signal $\left(R_{\mathrm{S}} / R_{0}\right)$ and other predictors. An advantage of calibrating sensors in the field as opposed to in a laboratory setting is that the models will be trained for the pollutant levels of interest and across the same dynamic temperature and humidity values that a sensor will likely experience during field deployment. In a study involving personal air quality monitors, Piedrahita et al. (2014) successfully calibrated sensors and provided sensor-specific uncertainty estimates using this method.

In Colorado, we co-located U-Pods with a Los Gatos cavity ring-down spectrometer operated by the Penn State Native Trailer team at the Platteville Atmospheric Observatory in Platteville, CO. In Los Angeles, we co-located Y-Pods with reference instruments at two different sites. The predeployment co-location was with a Baseline Mocon Series 900 Methane/Non-methane Hydrocarbon Analyzer located in a primarily residential suburban area of Los Angeles. The post-deployment calibration was with a Picarro cavity ringdown spectrometer located in a suburban/urban area with a mix of residential, retail, and industrial land use. Reference instruments at both Los Angeles sites were operated by the
South Coast Air Quality Management District. The timelines in Figs. 4 and 5 illustrate when pods were co-located vs. deployed in the field and which data were used for the generation of calibration models (i.e., training data) versus the validation of those models (i.e., testing data). Note that for the Colorado deployment, both before and after the field deployment, the monitors were co-located in batches due to logistical constraints. Arrows indicate the movement of batches of monitors, and the "not in use" row clarifies whether pods were deployed. In addition, during the Colorado deployment, a single calibration model (a universal model) was developed based on the data from the "main" U-Pod, described in greater detail below. For the Los Angeles deployment, calibration models specific to each Y-Pod (sensor-specific models) were used.

The setup of Y-Pods for these co-locations was governed by limitations at the site. In Colorado, Y-Pods were mounted to the railing of the Native Trailer (approximately $1.5 \mathrm{~m}$ above the trailer roof), which housed the reference instruments. The inlets to the reference instruments were approximately $2.5 \mathrm{~m}$ above the roof of the trailer and roughly $2 \mathrm{~m}$ away from the Y-Pods. For the first co-location in Los Angeles, the reference instrument was housed in a trailer in an open field. As we were not able to place the Y-Pods on the roof of the trailer, they were placed $0.75-1.5 \mathrm{~m}$ off the ground on the side of the trailer where the inlet was mounted. In this case, the Y-Pods were roughly $6 \mathrm{~m}$ below and $3 \mathrm{~m}$ to the side of the inlet. For the second co-location in Los Angeles, the reference instruments were housed inside of a building. In this case the Y-Pods were mounted to a railing roughly $1-2 \mathrm{~m}$ off the roof. However, the Y-Pods were also approximately $10 \mathrm{~m}$ away from and $1-2 \mathrm{~m}$ below the inlet, as this location was secure and out of the way of ongoing operations at the reference site. We would expect the variability between colocation setups to be most important for short-term spikes in $\mathrm{CH}_{4}$ that do not pass over the Y-Pod and inlet evenly. As discussed in Sect. 3.1, our co-location site in Colorado experienced the most short-term $\mathrm{CH}_{4}$ spikes, whereas the changes in $\mathrm{CH}_{4}$ concentration at the two LA sites were more gradual in nature.

For both deployments, 4 days of data at the beginning and 4 days at the end of the co-location with reference instruments were used to generate the calibration models. Specifically, for Colorado, 4 days at the beginning and end of the field deployment were used for generating the quantification model. In Los Angeles, 4 days from both the pre- and postco-location were used for model generation. The remaining data from co-locations were then used for model validation (approximately 18 days for Colorado and 4 days for LA). Table 1 lists the calibration models that were compared. Several models (the simpler ones) selected are commonly used in sensor calibration, while the more complicated models were selected based on predictors that aided in correcting for cross sensitivity and resulted in more normal residuals. The models are listed in order of their complexity, beginning with the 


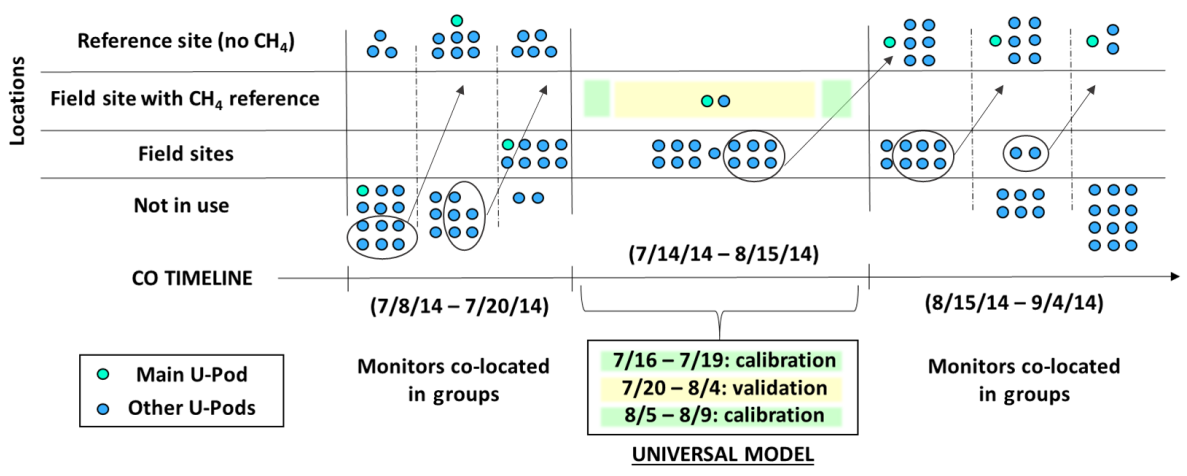

Figure 4. Timeline for Colorado, indicating when monitors were co-located together in batches before and after the field deployment and illustrating how two U-Pods were sited with a reference instrument during the field deployment (these data were used for calibration generation or training data versus model validation or testing data).

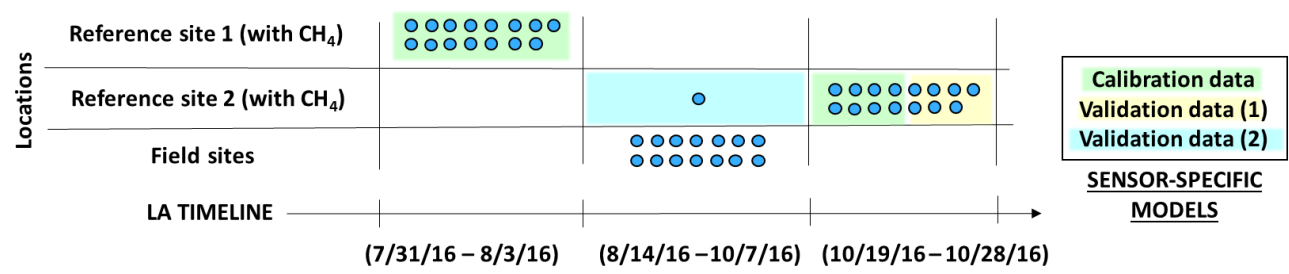

Figure 5. Timeline for LA indicating when Y-Pods were co-located together with reference instruments before and after the field deployment, as well as which data were used for calibration generation (training data) versus model validation (testing data).

addition of environmental parameters, then interactions, and then transformations. Regression analysis provides sensorspecific coefficients for predictor variables. The models are then inverted so that gas concentration is expressed as a function of sensor signals and can then be used to predict pollutant concentrations using new data collected in the field. This inverted model approach is typical for field normalization (Piedrahita et al., 2014; Spinelle et al., 2015, 2017). Evaluation of model performance was based on the coefficient of determination $\left(R^{2}\right)$ and the root mean squared error (RMSE), as well as an analysis of the residuals in relation to relevant environmental and air quality parameters. Validation data provide the opportunity to evaluate the consistency of each model's performance based on the same metrics and the addition of mean bias.

Given the structure of each deployment and availability of co-located data, two different approaches to developing and applying calibration models were used: a universal calibration model vs. sensor-specific models. For the Colorado deployment, a universal calibration model was developed using the data from one sensor and this model were applied to all the sensors. As shown in Fig. 4, two U-Pods were colocated with the reference instrument throughout the field deployment. The data from one of these pods was used along with the following process: (1) generate a universal calibration model using data from the main U-Pod co-located with the reference instrument; (2) normalize all of the other U-
Pods' raw sensor signals to the main U-Pod using data from when they were co-located together before and after the field deployment; and (3) apply the universal calibration model to the normalized sensor data from each pod. The second UPod co-located with the reference instrument allows for validation of this method.

For the Los Angeles deployment, sensor-specific calibration models unique to each Y-Pod were used. As shown in Fig. 5, the Y-Pods were all co-located together with reference instruments before and after the field deployment providing the opportunity to generate and use sensor-specific models. Additionally, one Y-Pod in Los Angeles was deployed with a reference instrument throughout the field deployment providing an additional set of validation data (referred to as Validation 2). These data offer the opportunity to calibrate the Los Angeles data using both sensor-specific calibration models and a universal calibration model - a direct comparison demonstrating the relative performance of these two methods. This offers an informative comparison as there may be instances where only one method is possible given logistics, such as access to reference instruments. Another advantage to this universal calibration model approach would be that the calibration model is not extrapolating in time as the training data would cover the complete field deployment period. 
Table 2. Calibration models.

\begin{tabular}{lll}
\hline Model no. & Description & Model equation \\
\hline 1 & Md11 & $R_{\mathrm{S}} / R_{0}=p_{1}+p_{2}(C)$ \\
2 & Md13 & $R_{\mathrm{S}} / R_{0}=p_{1}+p_{2}(C)+p_{3}(T)+p_{4}(H)$ \\
3 & Md14 & $R_{\mathrm{S}} / R_{0}=p_{1}+p_{2}(C)+p_{3}(T)+p_{4}(H)+p_{5}\left(T_{i}\right)$ \\
4 & Md14_1Int & $R_{\mathrm{S}} / R_{0}=p_{1}+p_{2}(C)+T\left(p_{3}+p_{6}(C)\right)+p_{4}(H)+p_{5}\left(T_{i}\right)$ \\
5 & Md14_2Int & $R_{\mathrm{S}} / R_{0}=p_{1}+p_{2}(C)+T\left(p_{3}+p_{6}(C)\right)+p_{4}(H)+p_{5}\left(T_{i}\right)+p_{7}(T \times H)$ \\
6 & Md14_1Int_Tr & $R_{\mathrm{S}} / R_{0}=p_{1}+p_{2}(C)+T\left(p_{3}+p_{6}(C)\right)+p_{4}(\ln (H))+p_{5}\left(T_{i}\right)$ \\
7 & Md14_2Int_Tr & $R_{\mathrm{S}} / R_{0}=p_{1}+p_{2}(C)+T\left(p_{3}+p_{6}(C)\right)+p_{4}\left(H^{-1}\right)+p_{5}\left(T_{i}\right)+p_{7}\left(T \times H^{-1}\right)$ \\
8 & Md15_1Int & $R_{\mathrm{S}} / R_{0}=p_{1}+p_{2}(C)+T\left(p_{3}+p_{6}(C)\right)+p_{4}(H)+p_{5}\left(T_{i}\right)+p_{7}\left(T_{d}\right)$ \\
9 & Md15_2Int & $R_{\mathrm{S}} / R_{0}=p_{1}+p_{2}(C)+T\left(p_{3}+p_{6}(C)\right)+p_{4}(H)+p_{5}\left(T_{i}\right)+p_{7}(T \times H)+p_{8}\left(T_{d}\right)$ \\
10 & Md15_1Int_Tr & $R_{\mathrm{S}} / R_{0}=p_{1}+p_{2}(C)+T\left(p_{3}+p_{6}(C)\right)+p_{4}(\ln (H))+p_{5}\left(T_{i}\right)+p_{7}\left(T_{d}\right)$ \\
11 & Md15_2Int_Tr & $R_{\mathrm{S}} / R_{0}=p_{1}+p_{2}(C)+T\left(p_{3}+p_{6}(C)\right)+p_{4}\left(H^{-1}\right)+p_{5}\left(T_{i}\right)+p_{7}\left(T \times H^{-1}\right)+p_{8}\left(T_{d}\right)$ \\
\hline
\end{tabular}

Predictors (lower case $p$ with subscripts): $C$ is pollutant concentration (ppm methane), $T$ is temperature, $H$ is absolute humidity, $T_{i}$ is continuous time, and $T_{d}$ is categorical time of day; Mdl indicates the number of predictors; Int indicates the number of interactions; Tr indicates use of transformations. The predictor $p_{1}$ indicates an empirical constant.

\section{Results and discussion}

\subsection{Differences in reference data and environmental conditions that impact calibration}

Different sampling environments necessitate the use of different strategies to produce the strongest calibration for each dataset. Reasons for this may be differences in local sources or metrological trends. Figure $6 \mathrm{a}$ and $\mathrm{b}$ illustrate the difference in temperature and humidity values observed during calibration versus validation periods for both locations. In Colorado, the temperature and absolute humidity observed during the validation period are generally well represented by the data collected during the calibration period, although there are some high and low humidity values at certain temperatures that fall outside of the calibration parameter space. Conversely, in Los Angeles, the full range of temperature and humidity values observed during the validation period are captured in the calibration period. However, the Los Angeles data have many temperature-humidity combinations that are unique to the validation period.

Other sensor limitations must be considered as well, for example relatively slow sensor response. A low-cost sensor with an operating principle relying on chemical reactions may not have time to fully detect a passing plume (Arfire et al., 2016), whereas this is not an issue for high-quality reference instruments that rely instead on optical properties. The manufacturer of the Picarro cavity ring-down spectrometer, for example, cites a gas response time under $3 \mathrm{~s}$ (Picarro, Inc., 2015), while Baseline Mocon cites a response time of less than $5 \mathrm{~s}$ for the Series 900 Methane/Non-methane Hydrocarbon Analyzer (Mocon, Inc., 2017). Given these quick response times and the high flow rates used for sampling by the reference instruments we would not expect a lag on the part of the reference instrument. The sensor failing to reach steady state when exposed to a short and high concentration plume, as a result of slow sensor response, would be more of a concern for calibration. This limitation may result in sensor data that are fundamentally different from reference data, further complicating calibration model generation. One option for addressing this issue, explored below, is filtering short-duration reference data features prior to model generation. Demonstrating the need for this step, Fig. $6 \mathrm{~d}$ and e each show 3 days of data from the reference monitors in which the diurnal patterns are similar, but the Colorado data also include short-term enhancements or "spikes" in methane possibly from the oil and natural gas extraction activity in the study region. The histogram in Fig. $6 \mathrm{c}$ depicts the changes in methane values for each dataset from minute to minute, further highlighting instances in the Colorado data where methane levels change by 0.5 or even $1 \mathrm{ppm}$ over the course of a minute. These differences in the environmental parameter spaces emphasize the need to customize quantification methods to each dataset.

\subsection{Comparing calibration models}

Table 3 contains the resulting statistics for each of the models described in Table 2 for one Colorado U-Pod and three Los Angeles Y-Pods. Three Y-Pods were selected randomly to facilitate analysis of the universal model method and provide an initial indication of calibration model consistency across different sensors. This table lists the $R^{2}$ and the RMSE as well as the mean bias for the validation data. In all cases, these are the statistics for the fitted sensor data (converted into $\mathrm{ppm} \mathrm{CH}_{4}$ ) versus the reference methane data. Note that the second value in the Colorado data is the result when a filter is used to remove short-term spikes from the reference and sensor data. Filtering the Los Angles reference data did not change any of the statistics for that dataset and therefore was not performed. This filter removes spikes that are greater 

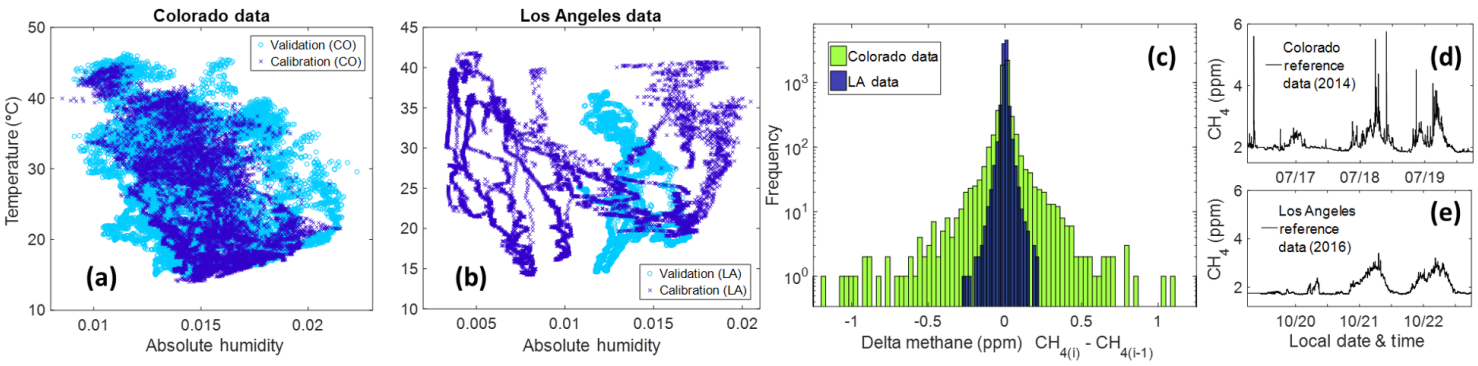

Figure 6. Panels (a) and (b) are the temperature and humidity values observed during calibration and validation periods in Colorado and Los Angeles, respectively. Panel (c) is a histogram of the changes in methane from minute to minute (for the reference data) and panels (d) and (e) are 3 days of minute-resolution data from the reference instruments in Colorado and Los Angeles, respectively.

than twice the past hour's standard deviation and last less than $5 \mathrm{~min}$ in duration.

Figure $7 \mathrm{a}$ and $\mathrm{b}$ provide a graphical representation of the same statistics from Table 3 and emphasize the differences in results between the two datasets. For the Colorado data, the greatest improvement in fit was observed when time was added as a predictor, but then the results level off with no major improvements as the models increase in complexity. However, the results consistently returned a higher $R^{2}$ and lower RMSE when short-term methane spikes were filtered prior to model generation. In the Los Angeles dataset, there was continual improvement as models increased in complexity, with the most complex model producing a high $R^{2}$ and low RMSE as well as the most consistency across both the calibration and validations datasets.

Figures 8 and 9 provide plots of the "best-fitting" calibration models for each dataset based on regression statistics, consistency across calibration and validation data, and an analysis of the residuals. For the Colorado data, the selected model was the simplest well-fitting model, the fourth model, while for the Los Angeles data the selected model was the most complex model tested, the 11th model. With regards to both datasets, the selected model produced the most normal residuals, which also did not exhibit major trends in relation to the predictors, and they resulted in the closest one-to-one relationship between the fitted sensor data and the reference data. The time series plots also display the performance of the calibration model on the validation dataset.

As demonstrated by these two datasets, calibration models are not "one size fits all". While the deployments in Los Angles and Colorado occurred at roughly the same time of year, the best-fitting calibration models and regression results proved to be quite different. This speaks to the need to consider the environmental and pollutant parameter space both when planning a deployment and when processing data. For example, more complex temperature and humidity behavior may require more complex corrections. Additionally, if there is little overlap between conditions observed during calibration, validation, and field deployment then the resulting calibrations will be less dependable. Likely, there are factors beyond environmental parameter space driving differences between sensor and reference data. In that vein, it is important to explore the operational differences between the reference instrument and the sensors, including distance apart and proximity to significant sources. Here, we compensated for those operational differences by filtering "spikes" from the reference data; another modification could be to use a different averaging time such as hourly instead of minute data. This analysis demonstrates the importance of exploring different models, transformations of variables, and treatments of the data to find the model that provides the strongest methane estimates.

One feature of the models that applied to both datasets was a correction for sensor drift over time, emphasizing the importance of collecting data that either bookend or span the duration of the field deployment. Even though the final models selected here differed, both included a correction for sensor drift over time and a pre-only or post-only calibration would not have allowed for this correction. To examine the consistency of this drift between sensors, we compared the linear drift from the three LA Y-Pods by examining data converted to concentrations using Mdl3, which does not include time as a predictor. The results were drift values of 0.009 , 0.015 , and $0.011 \mathrm{ppm}^{-1 e \mathrm{k}^{-1}}$ for LA1, LA2, and LA3, respectively. While these numbers are similar to those reported by Eugster and Kling (2012), the total drift implied is less than or equal to our expected uncertainty for each Y-Pod making the estimates unreliable. Given the differences in the deployments and their lengths, we have a starting idea of drift and its consistency sensor to sensor, but a better understanding of drift as well as the effective lifetime of sensors will be important for future use of this and other MOx sensors.

\subsection{Sensor-specific vs. universal calibration models}

The additional validation data (Validation 2) collected during the field deployment in Los Angeles facilitates a comparison of the sensor-specific versus the universal calibration model approach. Several calibration models were generated using this additional co-located data (Fig. 5), including the two models selected in the previous section as "best-fitting". 
Table 3. Calibration model generation and validation results.

\begin{tabular}{|c|c|c|c|c|c|c|c|}
\hline \multirow[b]{2}{*}{ No. } & \multirow[b]{2}{*}{ Model } & \multirow[b]{2}{*}{ POD } & \multicolumn{2}{|c|}{ Calibration data } & \multicolumn{3}{|c|}{ Validation data } \\
\hline & & & $R^{2}$ & RMSE (ppm) & $R^{2}$ & RMSE (ppm) & Mean bias \\
\hline \multirow[t]{4}{*}{1} & \multirow[t]{4}{*}{ Mdl1 } & CO; Filt. & $0.463 ; 0.469$ & $0.391 ; 0.369$ & $0.456 ; 0.459$ & $0.398 ; 0.378$ & $0.014 ; 0.007$ \\
\hline & & LA 1 & 0.244 & 0.561 & 0.550 & 0.438 & -0.381 \\
\hline & & LA 2 & 0.257 & 0.541 & 0.556 & 0.444 & -0.388 \\
\hline & & LA 3 & 0.229 & 0.582 & 0.552 & 0.434 & -0.379 \\
\hline \multirow[t]{4}{*}{2} & \multirow[t]{4}{*}{ Mdl3 } & CO; Filt. & $0.498 ; 0.507$ & $0.367 ; 0.346$ & $0.329 ; 0.331$ & $0.576 ; 0.550$ & $-0.035 ;-0.040$ \\
\hline & & LA 1 & 0.514 & 0.310 & 0.402 & 0.240 & 0.024 \\
\hline & & LA 2 & 0.522 & 0.304 & 0.434 & 0.248 & -0.079 \\
\hline & & LA 3 & 0.552 & 0.286 & 0.481 & 0.225 & 0.003 \\
\hline \multirow[t]{4}{*}{3} & \multirow[t]{4}{*}{ Mdl4 } & CO; Filt. & $0.574 ; 0.590$ & $0.314 ; 0.292$ & $0.392 ; 0.401$ & $0.483 ; 0.453$ & $-0.038 ;-0.035$ \\
\hline & & LA 1 & 0.500 & 0.319 & 0.380 & 0.252 & 0.070 \\
\hline & & LA 2 & 0.479 & 0.331 & 0.368 & 0.249 & 0.045 \\
\hline & & LA 3 & 0.526 & 0.301 & 0.438 & 0.250 & 0.096 \\
\hline \multirow[t]{4}{*}{4} & \multirow[t]{4}{*}{ Mdl4_1Int } & CO; Filt. & $0.596 ; 0.625$ & $0.300 ; 0.271$ & $0.423 ; 0.449$ & $0.437 ; 0.383$ & $-0.024 ;-0.011$ \\
\hline & & LA 1 & 0.747 & 0.184 & 0.518 & 0.224 & 0.047 \\
\hline & & LA 2 & 0.765 & 0.176 & 0.558 & 0.212 & 0.026 \\
\hline & & LA 3 & 0.752 & 0.181 & 0.527 & 0.225 & 0.069 \\
\hline \multirow[t]{4}{*}{5} & \multirow[t]{4}{*}{ Mdl4_2Int } & CO; Filt. & $0.588 ; 0.618$ & $0.305 ; 0.275$ & $0.432 ; 0.462$ & $0.441 ; 0.384$ & $-0.019 ;-0.011$ \\
\hline & & LA 1 & 0.753 & 0.181 & 0.496 & 0.229 & 0.053 \\
\hline & & LA 2 & 0.776 & 0.171 & 0.536 & 0.218 & 0.035 \\
\hline & & LA 3 & 0.752 & 0.181 & 0.527 & 0.226 & 0.067 \\
\hline \multirow[t]{4}{*}{6} & \multirow[t]{4}{*}{ Mdl4_1Int_Tr } & CO; Filt. & $0.593 ; 0.622$ & $0.302 ; 0.273$ & $0.425 ; 0.451$ & $0.440 ; 0.385$ & $-0.034 ;-0.019$ \\
\hline & & LA 1 & 0.737 & 0.189 & 0.512 & 0.341 & 0.264 \\
\hline & & LA 2 & 0.761 & 0.177 & 0.457 & 0.389 & 0.316 \\
\hline & & LA 3 & 0.745 & 0.184 & 0.525 & 0.380 & 0.316 \\
\hline \multirow[t]{4}{*}{7} & \multirow[t]{4}{*}{ Mdl4_2Int_Tr } & CO; Filt. & $0.588 ; 0.616$ & $0.305 ; 0.275$ & $0.440 ; 0.465$ & $0.430 ; 0.379$ & $-0.041 ;-0.027$ \\
\hline & & LA1 & 0.784 & 0.167 & 0.627 & 0.198 & 0.061 \\
\hline & & LA2 & 0.813 & 0.151 & 0.667 & 0.202 & 0.096 \\
\hline & & LA3 & 0.776 & 0.169 & 0.655 & 0.217 & 0.120 \\
\hline \multirow[t]{4}{*}{8} & \multirow[t]{4}{*}{ Md15_1Int } & CO; Filt. & $0.597 ; 0.625$ & $0.300 ; 0.271$ & $0.426 ; 0.451$ & $0.435 ; 0.382$ & $-0.021 ;-0.009$ \\
\hline & & LA 1 & 0.809 & 0.154 & 0.630 & 0.206 & 0.076 \\
\hline & & LA 2 & 0.812 & 0.153 & 0.635 & 0.202 & 0.070 \\
\hline & & LA 3 & 0.805 & 0.156 & 0.626 & 0.213 & 0.095 \\
\hline \multirow[t]{4}{*}{9} & Mdl5_2Int & CO; Filt. & $0.588 ; 0.618$ & $0.305 ; 0.274$ & $0.438 ; 0.466$ & $0.437 ; 0.382$ & $-0.014 ;-0.008$ \\
\hline & & LA1 & 0.827 & 0.146 & 0.571 & 0.225 & 0.092 \\
\hline & & LA2 & 0.833 & 0.142 & 0.580 & 0.222 & 0.091 \\
\hline & & LA3 & 0.819 & 0.149 & 0.579 & 0.229 & 0.108 \\
\hline 10 & Md5_1Int_Tr & CO; Filt. & $0.594 ; 0.622$ & $0.302 ; 0.272$ & $0.428 ; 0.453$ & $0.437 ; 0.384$ & $-0.032 ;-0.018$ \\
\hline & & LA1 & 0.800 & 0.158 & 0.709 & 0.282 & 0.225 \\
\hline & & LA2 & 0.807 & 0.154 & 0.630 & 0.341 & 0.285 \\
\hline & & LA3 & 0.795 & 0.160 & 0.678 & 0.332 & 0.281 \\
\hline 11 & Md15_2Int_Tr & CO; Filt. & $0.588 ; 0.617$ & $0.305 ; 0.275$ & $0.445 ; 0.467$ & $0.426 ; 0.377$ & $-0.038 ;-0.026$ \\
\hline & & LA1 & 0.820 & 0.149 & 0.756 & 0.160 & 0.040 \\
\hline & & LA2 & 0.831 & 0.143 & 0.734 & 0.180 & 0.083 \\
\hline & & LA3 & 0.804 & 0.156 & 0.731 & 0.190 & 0.104 \\
\hline
\end{tabular}

These models were then applied to normalized data from the other two Los Angeles Y-Pods included in the previous section. The raw sensor data from the Figaro TGS 2600 sensors were normalized using a simple linear regression (the $R^{2}$ values for these regressions were 0.989 and 0.999 , respectively).

Similar to the results from Sect. 3.2, the same model (MDL5_2INT_TR, model 11) emerges as the strongest for this particular dataset given that the validation statistics include the highest $R^{2}$ and lowest RMSE. An important note is that overall the results using this method are not as strong as the results seen using the sensor-specific models in the previous section. One reason for this may be that we are attempting to fit roughly 6 weeks, rather than 4 days, for the calibration model generation, meaning that the model is attempting 

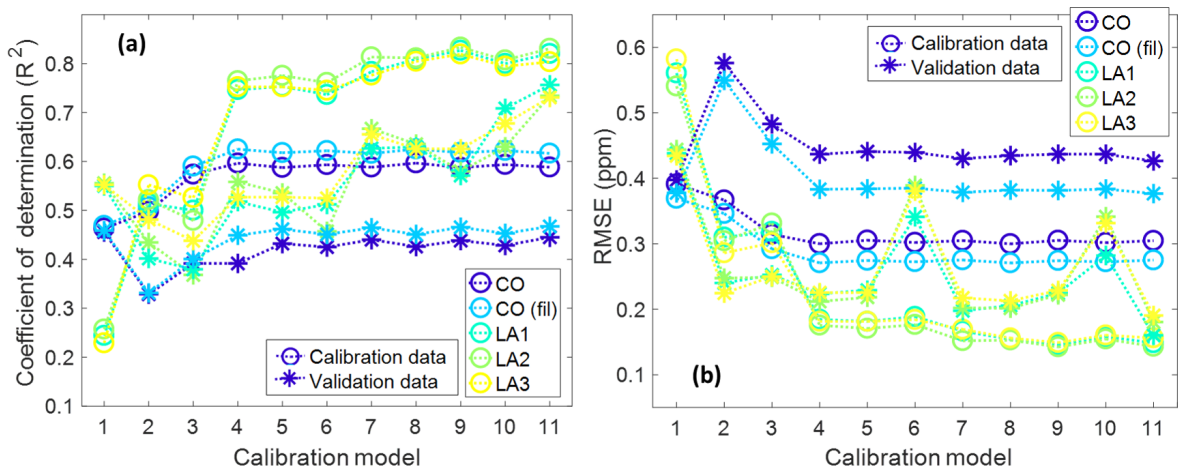

Figure 7. Plotted $R^{2}$ (a) and RMSE (b) for all models; circle markers indicate results from calibration generation (using the training data) and asterisk markers indicate results from the application of the models to the validation data (or testing data).
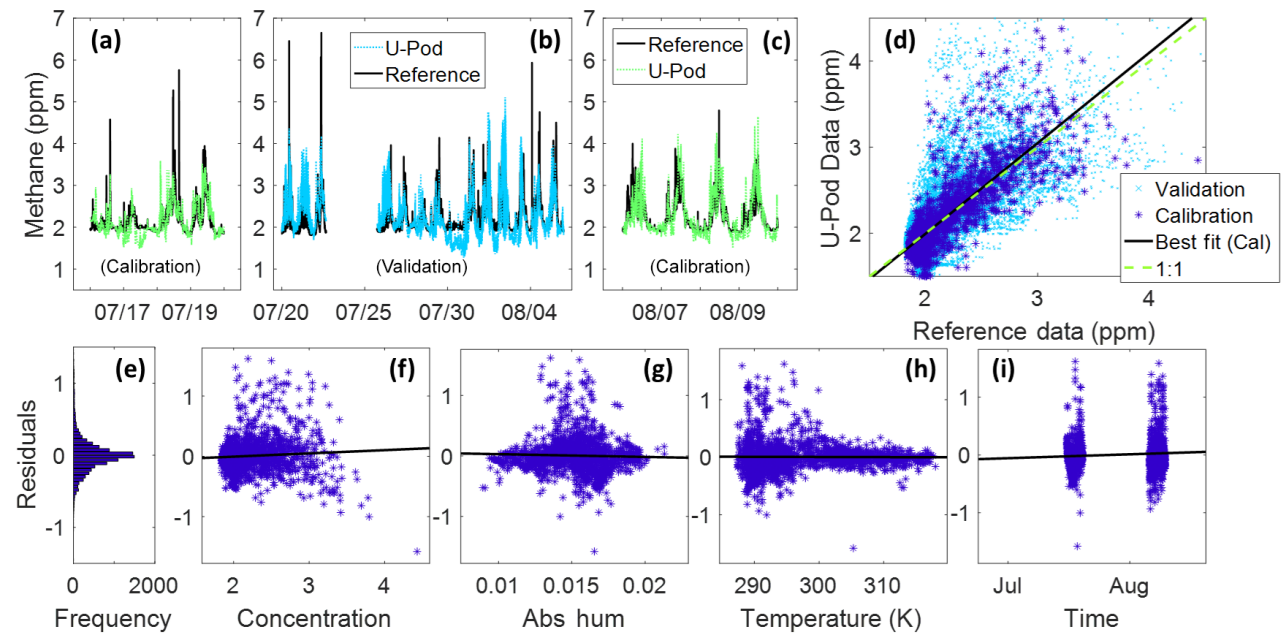

Figure 8. "Best-fitting" model (MDL4_1INT) for the Colorado data with residual analysis (for validation data, RMSE is 0.383 ppm and mean absolute percent error is $12.13 \%$ ). Panels (a-c) are time series of the reference data and converted sensor data. Panel (d) is a scatter plot of the same data. Panels (e-i) are the residuals from the calibration generation.

to cover a larger environmental parameter space. This might also explain why the results for the "best-fitting" model are better for the validation period, which is much shorter. In any case, this calibration model approach provides useful information regarding methane levels (e.g., diurnal trends), as is demonstrated by Fig. 10, and this method can be used to convert the normalized signals from other sensors to a ppm value when logistics limit the potential for co-locating all sensors, whether due to time constraints or the limited availability of power and/or space at a co-location site. As the logistics of the Colorado deployment did not allow for sensor-specific calibrations, the universal calibration model approach is used below in Sect. 3.5 to convert the Colorado field data from all the U-Pods.

\subsection{Further sensor quantification considerations}

Comprehensive best practices to guide the use of low-cost air quality sensors have not been established. A recent workshop for low-cost sensors outlined some of the concerns shared throughout the research community including deployment logistics, data formatting and sharing, and communication of uncertainty (Clements et al., 2017). With our datasets, we investigated three issues related to the development of best practices: the length of a co-location for a field normalization, additional dataset-specific filtering based on environmental parameters, and cross sensitivities to non-methane pollutants.

\subsubsection{Length of co-location}

Bootstrapping methods were applied to determine the variability and effectiveness of different co-location lengths for the Colorado data. A starting point in the complete dataset was randomly selected and consecutive data of varying lengths $(0.5,3,7$, or 14 days) were used to generate a calibration model. This model was then applied to the entire dataset for validation. For comparison purposes three differ- 

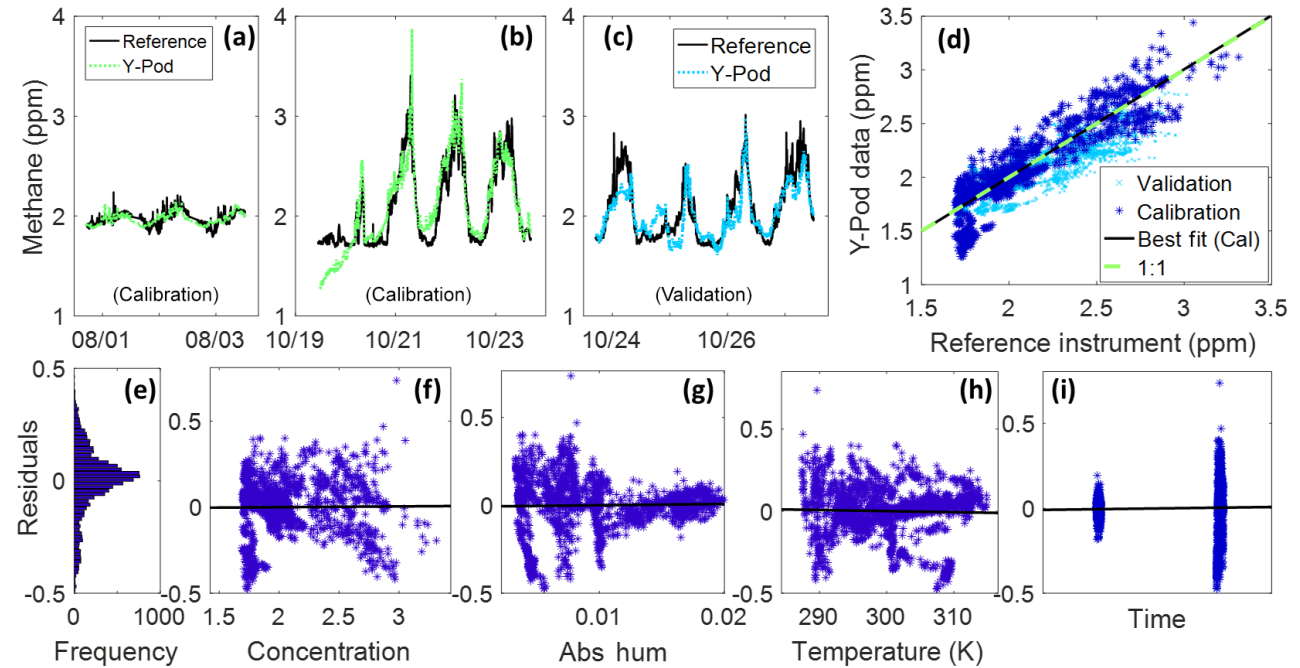

Figure 9. "Best-fitting" model (Md15_2Int_Tr) for the Los Angeles data with residual analysis (LA1 shown) (for validation data, RMSE is $0.160 \mathrm{ppm}$ and mean absolute percent error is $5.75 \%)$. Panels $(\mathbf{a}-\mathbf{c})$ are time series of the reference data and converted sensor data. Panel (d) is a scatter plot of the same data. Panels (e-i) are the residuals from the calibration generation.

Table 4. Calibration and validation results for the universal calibration method ${ }^{*}-$ normalized Y-Pod data).

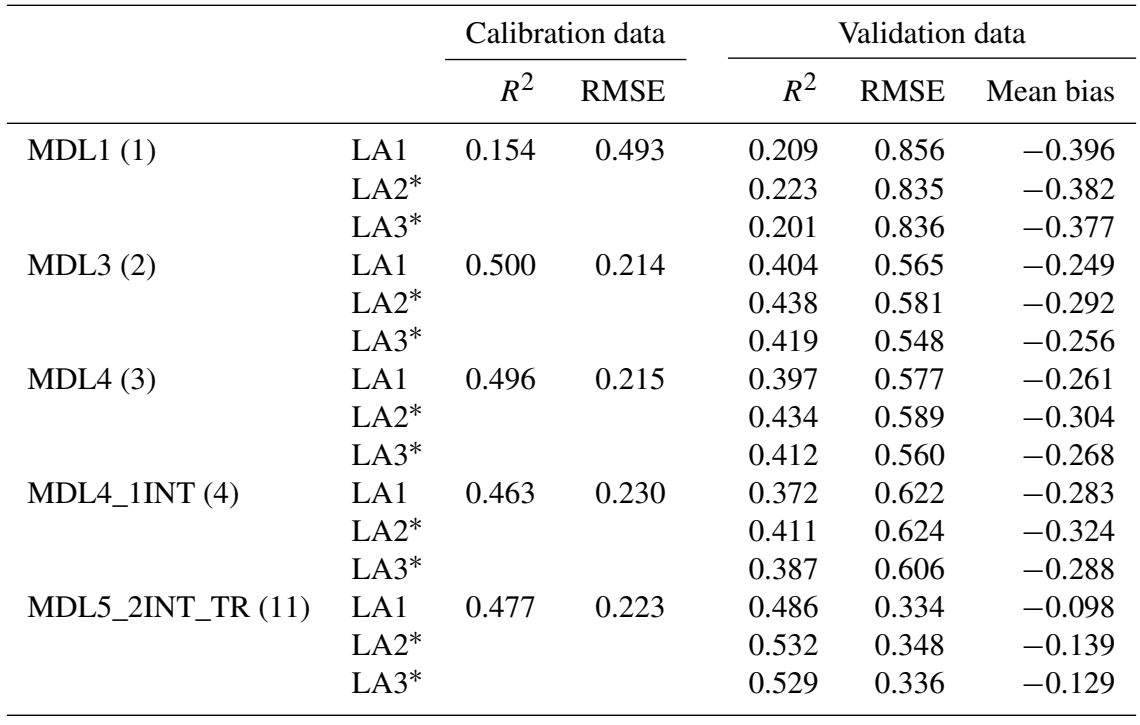

ent models were tested with 20 iterations for each model. The resulting statistics are plotted in Fig. 11 along with error bars for \pm 1 standard deviation.

The simplest model (Mdl1), using only sensor signal and no environmental predictors, seems to perform consistently well for all lengths of time; however, the residuals reveal strong trends with temperature and humidity, indicating that these variables are not being corrected for. Given the analysis of the residuals, this model may provide useful information, but its implementation is also likely to be misleading. For example, this model may be useful in applications that do not require detailed analysis or decision making based on the data, such as education and outreach in a K-12 classroom where sensors are used for labs or student projects (Collier et al., 2015). Taking into account residuals, Mdl3 provides some correction for temperature and humidity effects without overfitting on shorter co-location lengths. Mdl4_1Int, which includes time as a predictor, is the best performing model for co-location periods of 2 weeks. Given that time was a useful predictor in Sect. 3.2, the fact that the data are spanning 2 weeks is probably more important than having 2 full weeks of co-located data. This means that the co-location data must be long enough or span a long enough duration relative to the complete dataset in order to provide a time correction that does not lead to overfitting and poor performance on validation data. While greater complexity can pro- 

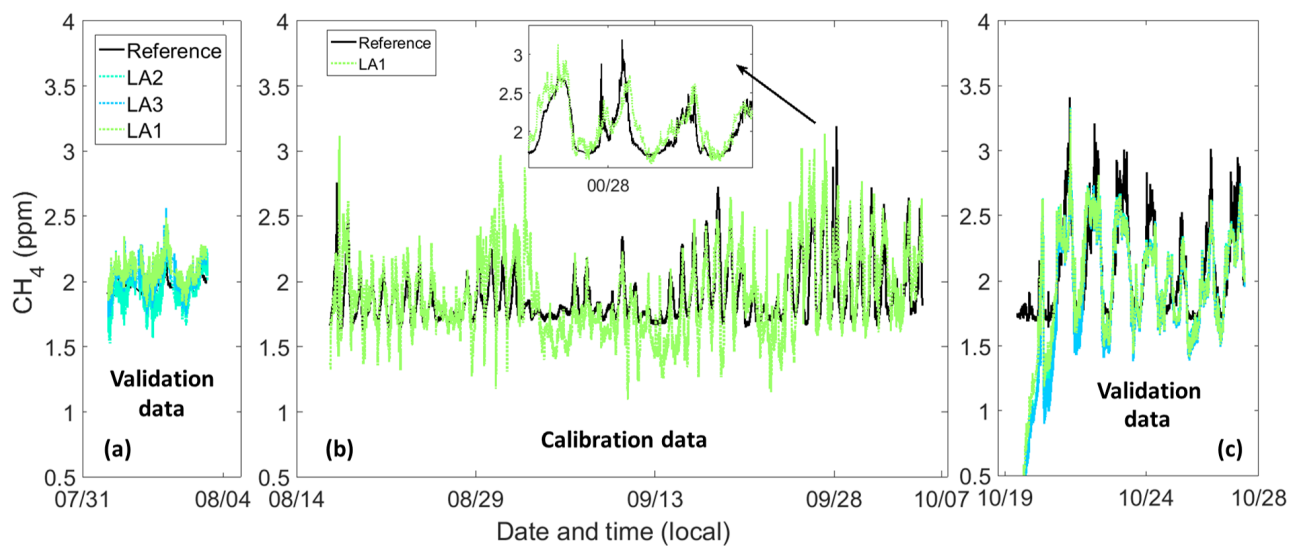

Figure 10. Time series of the universal calibration model (for MDL5_2INT_TR) generated using the Validation 2 period (b) and the application of the model to the pre- and post-deployment co-location data (a and c) for Y-Pods LA1 and the normalized data from LA2 and LA3.
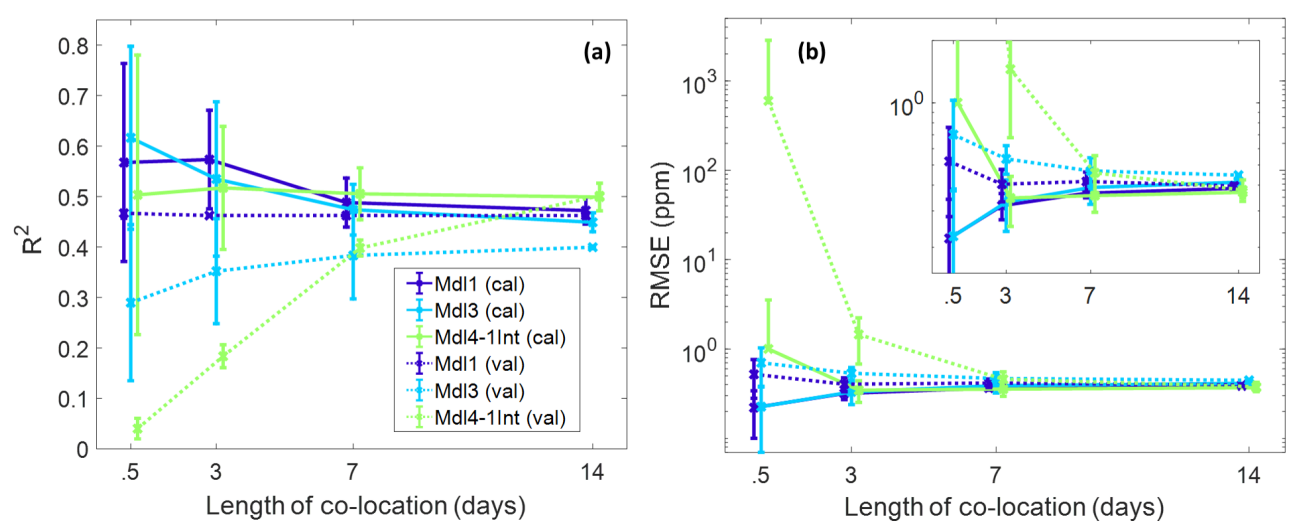

Figure 11. $R^{2}$ (a) and RMSE (b) for the calibration model generation (based on a given length of time) and the application of those models to the complete Colorado data. Note that calibration data, or training data, are selected using a random stating point in the complete Colorado dataset and the appropriate amount of consecutive data. The colors indicate the model, and solid lines indicate calibration results while dashed lines indicating validation results.

vide a better calibration model, a sufficient amount of data must be used to avoid overfitting. Simply stated, the model selection should be appropriate to the data's characteristics and intended purpose.

\subsubsection{The impact of model extrapolation}

The additional co-located data from Los Angeles (Validation 2) facilitate a more in-depth exploration of the outlier residuals and approaches that could improve the predictive power of the calibration model. For example, dataset-specific filters were applied to remove values where extrapolation is likely occurring in field data. Extrapolation in this case would be instances where one or more predictors are outside of the range of values used to train the calibration model. Table 5 provides the statistics that result from applying the calibration model with and without this added filtering. The unfiltered dataset statistics are the same results explored in Sect. 3.2. All other statistics in the table were calculated after values not observed during calibration were removed. In the first filtered grouping in Table 5, instances where individual temperature or humidity values (primarily extreme values) not observed were removed. In the second grouping, all data combinations not observed during calibration were removed, meaning all instances where exact combinations of temperature, humidity, etc. were not observed. The final filtering option, shown in the fourth section, applies knowledge of atmospheric composition to assist with filtering. In this instance, the atmospheric baseline of methane was used to filter out low concentration values; the baseline was determined by the minimum value observed in the $\mathrm{CH}_{4}$ reference data.

The final filtering approach should only be applied to sensor data selectively. Removing improbable values from sensor data that fall below zero or a known baseline may be a useful or even necessary strategy in certain situations. In dealing with air quality data, there are examples of additional 
processing being used to reduce negative values (Hagler et al., 2011) and examples of guidelines to remove negative values below a given threshold (US EPA, 2016). For work with sensor data, if the focus of the analysis is to understand enhancements over background captured by sensors, then removing improbably low values can elucidate these results. If preliminary data are being shared with the public, then flagging and removing improbable values can reduce confusion. Given the challenges in sensor quantification, this second example in particular warrants consideration by those using sensors in partnership with communities. However, it is also likely that these underestimations contain valuable information about sensor behavior and sensitivity; removing these values will also introduce a negative bias to the data. Accordingly, when using this type of processing, researchers will need to be clear about why this approach is useful and valid. For this dataset, every instance where underestimations are removed by the filter coincides with days having a dynamic range of methane less than the expected uncertainty for the sensor, which indicates that these underestimations may be connected to a limit of detection issue. Figure B1 (Appendix B) demonstrates this association.

Additional filtering at nearly each stage yields some improvement in statistics, with the removal of the complete data combinations not seen during calibration resulting in the largest improvements, but this method also removes a large portion of the data. The combination of applied knowledge of atmospheric composition and the removal of extreme individual values not observed during calibration yields improvements while maintaining a substantial amount of the data. This result, labeled "selected filtering", suggests that this more conservative version of filtering may be sufficient. Not only did this filtering result in a RMSE that is lower than the RMSE for first validation dataset $(0.1525$ and $0.1601 \mathrm{ppm}$, respectively), but also these improvements are visible in a plot of the data. Figure 12a provides an overview of the complete dataset and highlights where some of the underpredictions are corrected for before 7 and 17 September, likely driven by the filter utilizing atmospheric principles. Figure $12 \mathrm{~b}$ shows a close-up of a couple of days illustrating a reduction in overprediction, driven by the filter for either temperature, humidity, or resistance values.

As was demonstrated with the Validation 2 dataset, we expect that applying the same filtering to each deployed sensor's data should result in more reliable field data from all of the sites. Thus in addition to filtering data prior to calibration by removing short-duration enhancements in the reference data, filtering converted sensor data can improve the reliability of calibrated data. While the bounds for this type of filtering should be dataset-specific, this step could easily be an automated addition to low-cost sensor quantification procedures.

\subsubsection{Sensor cross sensitivities}

Another common concern for low-cost sensors is cross sensitivities to other gases, in addition to known cross sensitivities to environmental factors. As discussed by Eugster and Kling (2012), the Figaro TGS 2600 sensor is reported to be sensitive to carbon monoxide as well as a few other hydrocarbons (Figaro, 2005). This is not surprising, as each of these species can act as a reducing gas at the sensor surface and therefore also reduce the resistance to electron flow. While Eugster and Kling (2012) did not examine CO specifically given the absence of potential sources in their deployment area, they did perform an analysis of variance examining the effects of $\mathrm{CO}_{2}$ and found no significant impacts. We applied the same analysis techniques to minute-resolution data to examine the impacts of other gases, specifically $\mathrm{CO}, \mathrm{O}_{3}$, and a few VOCs. Given the information provided by the sensor manufacturer, we expected a cross sensitivity to $\mathrm{CO}$, but not to $\mathrm{O}_{3}$; this analysis provided an opportunity to check these assumptions. Table 6 includes the resulting explained variance from each ANOVA, all of which included environmental parameters and time along with the following differences: set 1 is $\mathrm{CH}_{4}$ only, set 2 is $\mathrm{CH}_{4}$ and $\mathrm{CO}$, set 3 is $\mathrm{CH}_{4}$ and $\mathrm{O}_{3}$, set 4 is $\mathrm{CO}$ only, and set 5 is the combined $\left(\mathrm{CH}_{4}+\mathrm{CO}\right)$ predictor.

The overall results varied between the deployments. For example, absolute humidity explained a high percentage of the variance in Los Angeles, while the temperature and humidity both played a role in the Colorado data. A commonality was that the sensor exhibits a cross sensitivity to $\mathrm{CO}$, but not to $\mathrm{O}_{3}$. In both cases, the inclusion of $\mathrm{O}_{3}$ resulted in a higher percentage of variance being attributed to the residuals, and the variance explained by the $\mathrm{O}_{3}$ concentrations was 0.3 and $2.7 \%$ for Los Angeles and Colorado, respectively. In contrast, the inclusion of $\mathrm{CO}$ in the ANOVA for the Colorado data resulted in a decrease of the variance explained by $\mathrm{CH}_{4}$ from $29.2 \%$ to a still significant $21.8 \%$, while $15.0 \%$ was explained by the new CO predictor. Notably, this set of parameters also resulted in the lowest portion of the variance being left to the residuals, suggesting that it provided the strongest set of among these five parameter sets. The inclusion of CO in the ANOVA for the Los Angeles data yielded somewhat different results with the explained variance dropping drastically for $\mathrm{CH}_{4}$ and being quite low for $\mathrm{CO}$ as well, at 2.6 and $4.2 \%$, respectively. This result is likely explained by the temporal correlation between the two gases obscuring the importance of each individually. The $\mathrm{CO}$ concentrations in Los Angeles were higher than those observed in Colorado and well correlated with the $\mathrm{CH}_{4}$ data as demonstrated in Fig. 13. Further supporting this conclusion, parameter set 5 included a combined " $\mathrm{CH}_{4}+\mathrm{CO}$ " term and resulted in a higher portion of the variance explained through this term at $19.8 \%$ versus $\mathrm{CH}_{4}$ alone $(16.8 \%)$ or $\mathrm{CO}$ alone $(18.1 \%)$. This set also resulted in the lowest portion of variance left to the residuals. The lack of correlation between the Colorado 
Table 5. Additional filtering to improve calibration model performance on field data. AH is absolute humidity, WS is wind speed, WD is wind direction, and AP is atmospheric principles.

\begin{tabular}{llrrrr}
\hline & Data & $R^{2}$ & RMSE & Mean bias & $n$ \\
\hline Unfiltered datasets & Calibration & 0.820 & 0.149 & -0.002 & 9822 \\
& Validation 1 & 0.756 & 0.160 & 0.040 & 5461 \\
& Validation 2 & 0.527 & 0.166 & -0.032 & 71411 \\
\hline Using only values & Temperature & 0.529 & 0.167 & 0.031 & 70340 \\
represented in the & AH & 0.529 & 0.166 & 0.031 & 71551 \\
calibration data & Resistance & 0.548 & 0.160 & 0.028 & 70851 \\
& WS, WD & 0.526 & 0.167 & 0.031 & 69578 \\
\hline Using only paired & Temperature, AH, resistance & 0.552 & 0.160 & 0.026 & 69473 \\
values seen in the & Temperature, AH & 0.564 & 0.157 & 0.030 & 51233 \\
calibration data & Temperature, AH, resistance & 0.574 & 0.160 & 0.063 & 20059 \\
& Temperature, resistance, WS, WD & 0.715 & 0.188 & 0.091 & 7645 \\
\hline Adding AP & CH 4 baseline applied & 0.552 & 0.160 & 0.047 & 71736 \\
\hline Selected filtering & Temperature, AH, resistance, AP & 0.581 & 0.153 & 0.041 & 69473 \\
\hline
\end{tabular}

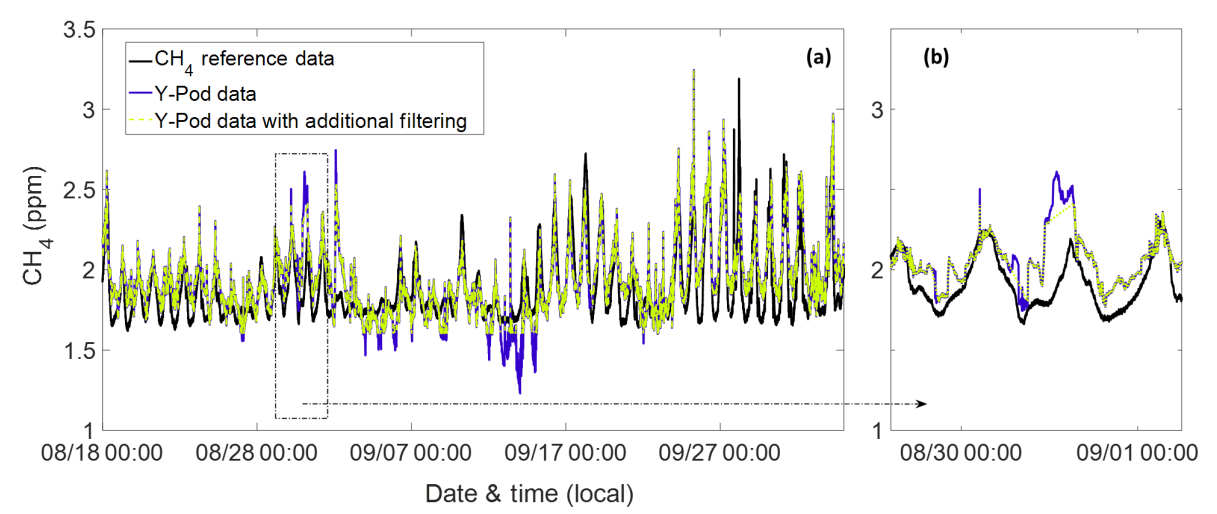

Figure 12. Panel (a) includes the complete Validation 2 dataset from the Los Angeles deployment. The statistics for each are RMSE is $0.17 \mathrm{ppm}$ and absolute percent relative error is $6.77 \%$ for the unfiltered data (blue); RMSE is $0.15 \mathrm{ppm}$ and absolute percent relative error is $6.19 \%$ for the filtered data (green), with the reference data plotted in black. Panel (b) is a close-up of approximately 2 days illustrating an instance where the filtering helped to reduce an overprediction of methane concentrations.

$\mathrm{CO}$ and $\mathrm{CH}_{4}$ allows us to examine the impacts of the $\mathrm{CO}$ cross sensitivity more closely. Figure 14 shows a portion of the Colorado data with both reference and U-Pod methane plotted along with carbon monoxide data from a reference monitor. In Fig. 14a spikes in CO correspond with overpredictions of methane (most notably on 8 August) and the scatter plot in Fig. 14b highlights how overpredictions seem to coincide with elevated $\mathrm{CO}$ concentrations.

In addition to this observed cross sensitivity to $\mathrm{CO}$, we expect that other hydrocarbons may affect the sensor response as well. This would be an important consideration for measurements made in areas with oil and gas activity where the pollutant mixtures may be complex. At the PAO site there was also a proton-transfer-reaction quadrupole mass spectrometry (PTR-QMS) providing speciated VOC measurements (Halliday et al, 2016). Future work will provide a more in-depth analysis of VOC sensitivity and selectivity for the two MOx sensors we are using; however, we have included here a preliminary look at this cross sensitivity to other hydrocarbons. Table 7 provides the results of another sensitivity analysis in which the explanatory power of a few speciated VOCs is examined. For simplicity, one VOC from different well-correlated groups was selected (e.g., benzene was selected out of the aromatic species). This analysis illustrates that VOCs (particularly acetaldehyde and benzene) do help to more fully explain the variance in the sensor signal, but they do not displace methane. This is most apparent for parameter sets 5 and 6 , in which we see the variance explained by residuals increase slightly and the variance explained by temperature increase quite a bit as this factor compensates for the missing methane. When methane is added back in for parameter set 7 , along with all three VOCs and $\mathrm{CO}$, the variance 
Table 6. Explained variance from ANOVA analyses on Figaro TGS 2600 resistance values $\left(R / R_{0}\right)$ for different parameter sets.

\begin{tabular}{|c|c|c|c|c|c|c|c|c|c|}
\hline \multirow[b]{2}{*}{ Source of variation } & \multicolumn{5}{|c|}{ Los Angeles } & \multicolumn{4}{|c|}{ Colorado } \\
\hline & Set 1 & Set 2 & Set 3 & Set 4 & Set 5 & Set 1 & Set 2 & Set 3 & Set 4 \\
\hline Temperature & $0.3 \%$ & $0.1 \%$ & $0.0 \%$ & $0.2 \%$ & $0.08 \%$ & $12.2 \%$ & $9.6 \%$ & $1.5 \%$ & $27.9 \%$ \\
\hline Absolute humidity & $61.5 \%$ & $72.5 \%$ & $63.7 \%$ & $61.5 \%$ & $62.4 \%$ & $6.8 \%$ & $10.2 \%$ & $10.6 \%$ & $6.4 \%$ \\
\hline Time & $0.0 \%$ & $0.0 \%$ & $0.1 \%$ & $0.0 \%$ & $0.0 \%$ & $8.3 \%$ & $8.9 \%$ & $10.8 \%$ & $3.7 \%$ \\
\hline $\mathrm{CH}_{4}$ & $16.8 \%$ & $2.6 \%$ & $14.2 \%$ & - & - & $29.2 \%$ & $21.8 \%$ & $20.5 \%$ & - \\
\hline $\mathrm{CO}$ & - & $4.2 \%$ & - & $18.1 \%$ & - & - & $15.0 \%$ & - & $19.2 \%$ \\
\hline $\mathrm{O}_{3}$ & - & - & $0.3 \%$ & - & - & - & - & $2.7 \%$ & - \\
\hline $\mathrm{CH}_{4}+\mathrm{CO}$ & - & - & - & - & $19.8 \%$ & - & - & - & - \\
\hline Residuals & $21.4 \%$ & $20.7 \%$ & $21.8 \%$ & $20.3 \%$ & $17.8 \%$ & $43.5 \%$ & $34.5 \%$ & $53.9 \%$ & $42.8 \%$ \\
\hline Total & $100.0 \%$ & $100.0 \%$ & $100.0 \%$ & $100.0 \%$ & $100.0 \%$ & $100.0 \%$ & $100.0 \%$ & $100.0 \%$ & $100.0 \%$ \\
\hline
\end{tabular}

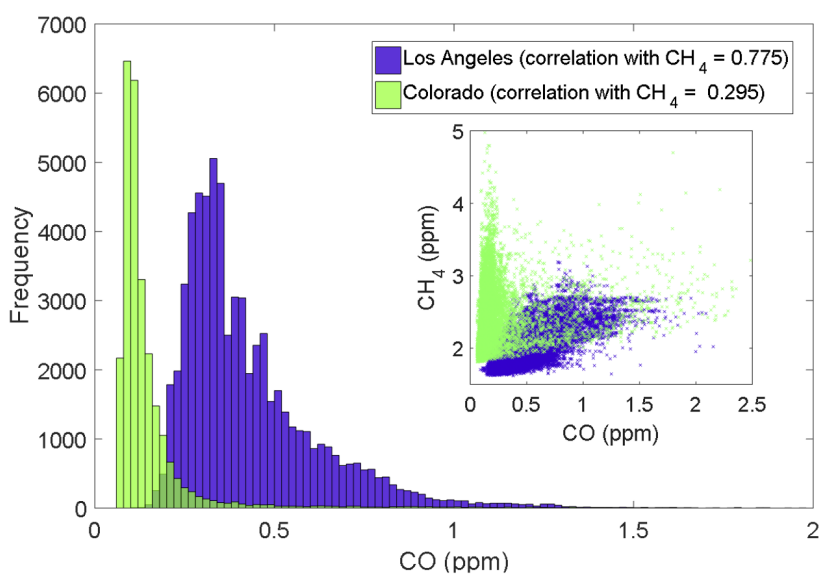

Figure 13. Histogram of carbon monoxide data from the two deployments and scatter plot of carbon monoxide data vs. methane data also from the two deployments. Note that all data in these two plots are from reference instruments.

explained by the residuals is at its lowest and the variance explained by methane is at $10.1 \%$, higher than the percentages for the individual hydrocarbons. Thus, the Figaro TGS 2600 sensor seems to be cross sensitive to carbon monoxide and some hydrocarbons, effects that should be considered or mitigated in future uses of this sensor to estimate methane.

Despite sampling in more complex environments than previous deployments of this sensor (Eugster and Kling, 2012), we are still seeing a sizable proportion of the sensor data's variance explained by ambient methane concentrations. Although these cross sensitivities need to be addressed to discern which signals are driven by methane versus other pollutants, the Figaro TGS 2600 sensors are reacting in part to changes in ambient methane again providing useful methane estimates for applications where methane concentrations are needed with resolutions on the order of $0.2-0.4 \mathrm{ppm}$. Given the variety of low-cost sensors available, using the Figaro TGS 2600 sensors in a sensor array could provide additional signals at each deployment site facilitating more re- liable data. Including multiple sensor signals in a neural network calibration approach may also improve the accuracy of the calibrated data (Zimmerman et al., 2018; De Vito et al., 2008; Huyberechts et al., 1997). Future analysis of the data collected in Los Angeles and continued use of this sensor in areas with complex mixtures will require carbon monoxide and non-methane hydrocarbon impacts be considered.

\subsection{Ability to assess spatial variability in the northern front range of Colorado}

The universal calibration approach along with the "bestfitting" calibration model (Fig. 8) was used to convert the field data from the sensors deployed in Colorado. Following the same procedure outlined in Sect. 2.4 and examined in Sect. 3.3, the raw voltage values from each Figaro TGS 2600 sensor, from the post-calibration period, were normalized to the sensor signals in U-Pod P1 (the main U-Pod) using sensor-specific simple linear fits. The calibration model was then applied to these normalized sensor data along with the temperature and humidity data from each U-Pod. An additional step was taken to detrend each set of converted sensor data by removing the best-fit linear trend from the whole dataset. It was necessary in this instance because the time correction incorporated in the calibration model appeared to be over- or under-correcting for different sensors. The choice to continue using this model was based on both the performance of the model observed in Sect. 3.2 and the fact that time appears to be a useful predictor for the Colorado data given the cross sensitivity analysis in Sect. 3.4.3. Data from the pre-calibration period when six sensors were co-located with U-Pod P1 were used to verify that the application of this detrend function was appropriately correcting for the underor over- correction of the model. One possible explanation for this difference in drift between the sensors is that 5 sensors were new and while the other 10 (including the one in U-Pod P1) had been previously deployed. This difference in drifts was not observed in the Los Angeles data (Sect. 3.3), which utilized all new sensors at the start of the deployment 

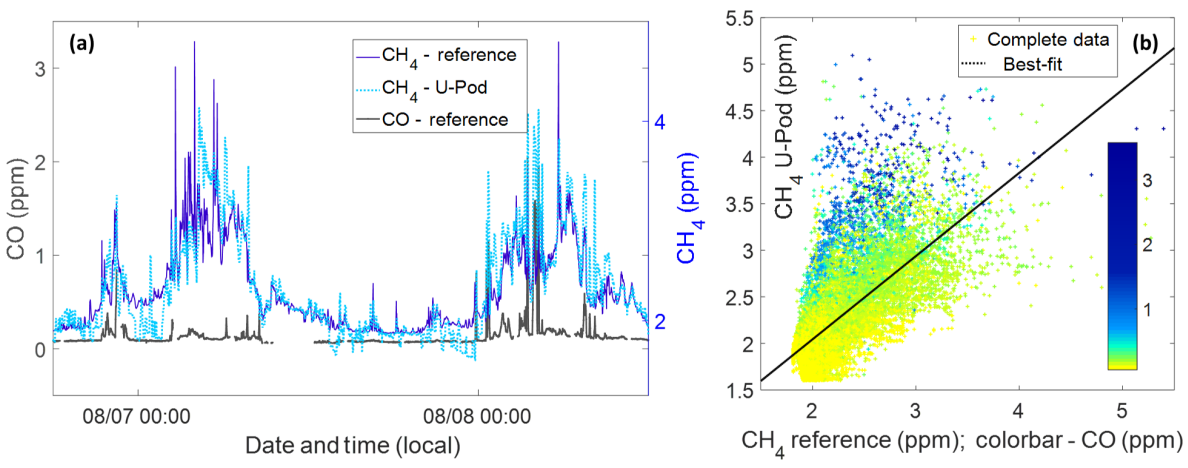

Figure 14. (a) Time series of methane and carbon monoxide data from the reference monitors and converted U-Pod sensor data. (b) Scatter plot of reference methane data ( $x$ axis) vs. U-Pod methane data ( $y$ axis) with the points colored by carbon monoxide vales. Together they further show the Figaro TGS 2600's cross sensitivity to carbon monoxide, illustrating how many over predictions correspond to instances when $\mathrm{CO}$ is at or above $0.5 \mathrm{ppm}$.

Table 7. Explained variance of the Figaro TGS 2600 resistance values $\left(R / R_{0}\right)$ for parameter sets including different VOCs.

\begin{tabular}{lrrrrrrr}
\hline Source of variation & Set 1 & Set 2 & Set 3 & Set 4 & Set 5 & Set 6 & Set 7 \\
\hline Temperature & $9.6 \%$ & $17.4 \%$ & $10.1 \%$ & $10.9 \%$ & $33.7 \%$ & $28.9 \%$ & $16.3 \%$ \\
Absolute humidity & $10.2 \%$ & $11.7 \%$ & $14.2 \%$ & $7.5 \%$ & $6.2 \%$ & $9.0 \%$ & $12.6 \%$ \\
Time & $8.9 \%$ & $4.5 \%$ & $9.2 \%$ & $4.4 \%$ & $3.0 \%$ & $2.8 \%$ & $5.8 \%$ \\
$\mathrm{CH}_{4}$ & $21.8 \%$ & $12.3 \%$ & $14.2 \%$ & $18.5 \%$ & - & - & $10.1 \%$ \\
$\mathrm{CO}$ & $15.0 \%$ & $13.6 \%$ & $14.4 \%$ & $19.7 \%$ & - & $9.8 \%$ & $11.4 \%$ \\
Acetaldehyde & - & $7.5 \%$ & - & - & $13.4 \%$ & $8.9 \%$ & $6.5 \%$ \\
Benzene & - & - & $4.6 \%$ & - & $8.4 \%$ & $6.4 \%$ & $4.0 \%$ \\
Methanol & - & - & - & $0.9 \%$ & $0.4 \%$ & $0.1 \%$ & $0.3 \%$ \\
Residuals & $34.5 \%$ & $33.0 \%$ & $33.4 \%$ & $38.2 \%$ & $34.9 \%$ & $34.1 \%$ & $33.2 \%$ \\
\hline Total & $100.0 \%$ & $100.0 \%$ & $100.0 \%$ & $100.0 \%$ & $100.0 \%$ & $100.0 \%$ & $100.0 \%$ \\
\hline
\end{tabular}

and were operated for the same amount of time throughout the deployment. The final step in preparing these data was to filter out data where the temperature and humidity values were outside of those ranges observed during calibration and to remove data where concentration values were lower than an expected minimum (atmospheric background) was observed, similar to the analysis in Sect. 3.4.2. In this case a conservative $1.6 \mathrm{ppm}$ was used, roughly half of our RMSE below background methane levels. For this analysis, filtering out implausibly low values highlights the differences in methane enhancements between the field sites. The largest amount of data removed from any U-Pod dataset as a result of this filtering was approximately $6 \%$.

Table 8 presents statistics illustrating the correlation coefficients and RMSE for converted sensor data during colocation versus field deployment for both the 2 U-Pods continuously paired and the mean of all 15 U-Pods. The result is high correlation when pods are co-located and low correlation when U-Pods are deployed to their field sites, highlighting that (1) there is consistency in the data provided through the universal calibration model and (2) we are seeing quite a bit of variability across the field sites. Addition- ally, the RMSE for co-located U-Pods is less than the error we expect given the RMSE of $0.3832 \mathrm{ppm}$ for the validation dataset. The details of each individual sensor versus $\mathrm{P} 1$ are available in Fig. A1 and Table A1, in Appendix A. These details demonstrate the extent of inter-sensor variability for colocated sensors and the increase in variability for deployed sensors. While there is some variability among correlation coefficients, for nearly all sensors the periods of enhanced methane fall along the 1:1 line and most offsets occur at lower methane concentrations. Additionally, all RMSEs for co-located sensor fall below our expected uncertainty, while the RMSEs for deployed sensors is larger than this uncertainty (with the exception of the P1-P2 pair, which was colocated during the deployment).

This process provided minute-resolution methane estimates from 15 field sites, allowing for analysis of spatial data over different temporal scales. For example, Fig. 15 includes roughly 2 days of data from four different deployment sites: P1 was our primary U-Pod located at the Platteville site, UPod E2 was located at the Boulder Atmospheric Observatory, U-Pod E3 was located at a water reclamation facility, and the U-Pod G1 was located at the Golden site. Even from this 
Table 8. Statistics for Colorado data converted using the universal model method.

\begin{tabular}{lrrrrr}
\hline & \multicolumn{2}{c}{ Post-co-location } & & \multicolumn{2}{c}{ Deployed to field sites } \\
\cline { 2 - 3 } \cline { 5 - 6 } & $R$ & RMSE (ppm) & & $R$ & RMSE (ppm) \\
\hline Co-located pair; P2 to P1 & 0.961 & 0.210 & & 0.904 & 0.241 \\
Mean of all U-Pods to P1 & 0.866 & 0.180 & & 0.025 & 0.556 \\
\hline
\end{tabular}

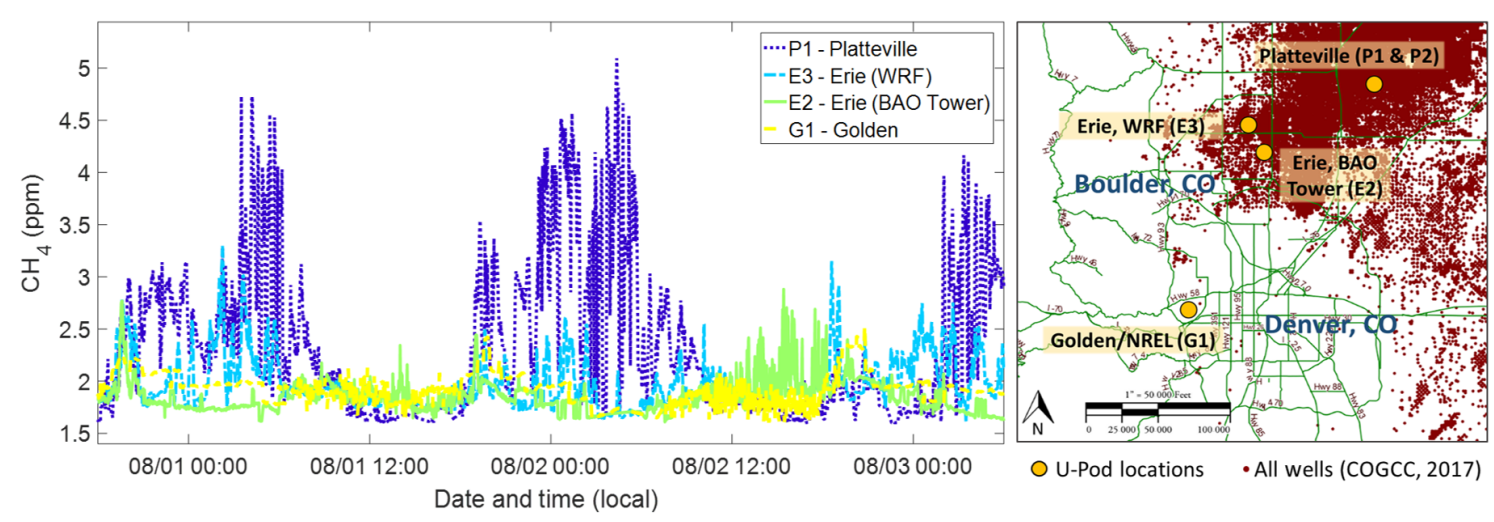

Figure 15. Time series of minute-resolution data from four Colorado sites and a map showing the location of the four U-Pod with respect to all active and inactive wells (COGCC, 2017).

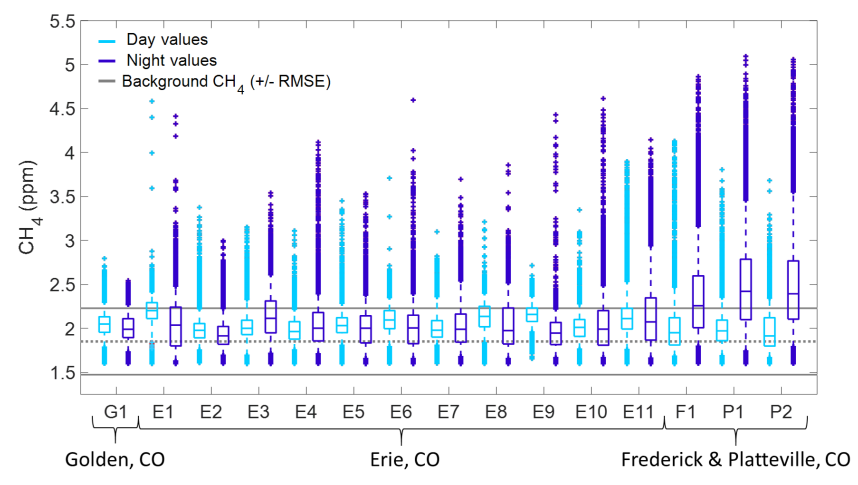

Figure 16. Box plots of all data for each U-Pod, grouped into daytime and nighttime values. Note that whiskers are the 5th and 95th percentile values. These U-Pods are then further grouped by region.

small time frame of data, we can see major differences between the sites. For example, there was a clear diurnal trend with elevated methane each night at the Platteville site. The high time resolution also allows us to observe short-term daytime increases at different sites, which were more sporadic and likely due to local emissions as there is typically more atmospheric mixing in the daytime (Bamberger et al., 2014). In contrast, the Golden site (U-Pod G1) exhibited relatively little variability in methane with differences between this site and the others well above our RMSE, suggesting significant differences in methane concentrations between these sites. Figure $15 \mathrm{~b}$ provides a reminder of where the oil and gas wells of the Wattenberg Field are in relation to these U-Pods. These high-resolution data (minute-median) allow for the study of individual emission events and possibly their correlation to nearby activity or regional trends.

Figure 16 shows the day and night methane concentrations for each site throughout the deployment, grouped by region. This figure also highlights the ambient background for methane \pm the U-Pod RMSE ( $0.3832 \mathrm{ppm}$ ) for this dataset on either side to illustrate that the enhancements above background were well beyond our expected error. The sensor in Golden (U-Pod G1) exhibited little variability across both daytime and nighttime values, whereas all the sites in Erie, Frederick, and Platteville exhibited larger ranges and larger nighttime increases in methane likely contributed to by local or regional sources. At the majority of sites, over $50 \%$ of the data fell within the RMSE of typical background levels of methane. Though the middle $50 \%$ of the nighttime data appears slightly shifted upward for U-Pods E11 and E3 in Erie (the two pods located near the water reclamation facility). This trend was even more pronounced at the sites in Frederick and Platteville. Recall the well density show in Figs. 2 and 15, illustrating no oil and gas activity around Golden, whereas we see higher-density activity in Erie and Frederick, with the highest density of activity around Platteville suggesting that one possible source driving this elevated methane is emissions from oil and gas activity. We observe this trend at night when atmospheric mixing is more limited and the planetary boundary layer is lower.

Figure 17 further illustrates this point by showing the difference in 90th percentile values between the main U-Pod 

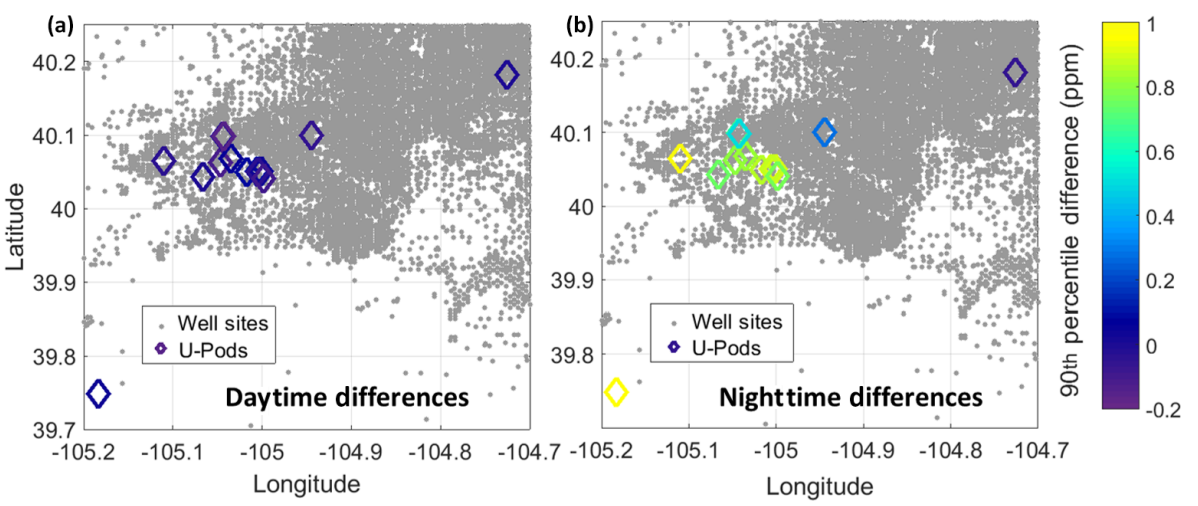

Figure 17. Well sites (COGCC, 2015) are plotted along with the differences between the 90th percentile value for the main Platteville U-Pod (P1) and every other U-Pod during the day (a) and night (b). The color bar indicates the magnitude of the difference in units of ppm $\mathrm{CH}_{4}$, and the same color bar scale is applied to both plots.

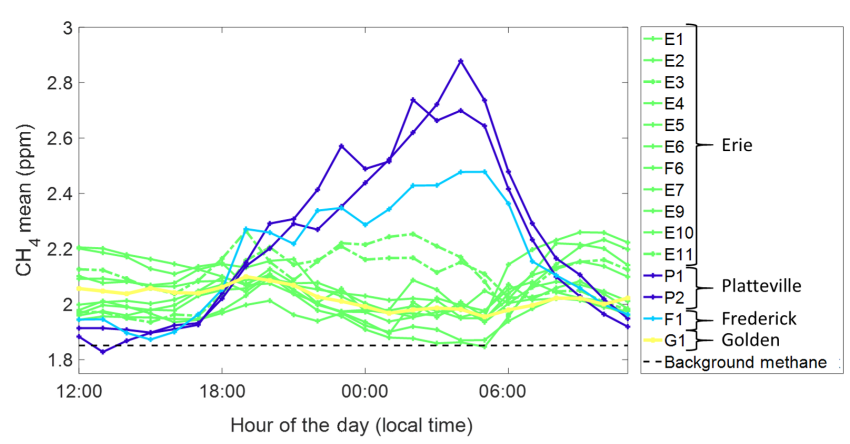

Figure 18. Mean methane value for each hour of the day, for each $\mathrm{U}-\mathrm{Pod}$, grouped and color-coded by region.

(P1) and all other U-Pods during the day (left) versus at night (right). The daytime differences are small, within $\pm 0.2 \mathrm{ppm}$ for all sites, possibly indicating effective daytime mixing. However, at night there is a clear gradient across the sites with little difference between the pods in Platteville and increasing differences as we move to the edge of the gas field and outside of it, with an approximately $1 \mathrm{ppm}$ difference for the Golden site and the site furthest west in Erie. Throughout the Erie field sites, the two U-Pods furthest north show the smallest difference with the Platteville pods after the Frederick pod, which was located much further into the gas field. These two pods were also the ones located at the water reclamation facility and therefore subject to an additional local methane source. Interestingly, however, the U-Pod furthest west in the Erie area was the only U-Pod in that grid located on the west side of the county line. This placed the pod in Boulder County during a time when a moratorium beginning in 2012 was in effect (Boulder County, 2017). This moratorium severely limited new oil and gas development in the county. Although we cannot conclusively say the observed difference in 90th percentile nighttime values is the result of differing methane trends on either side of the county line, it is an indication of a question possibly worth revisiting using other data collected during the FRAPPE/DISCOVERAQ campaigns. More importantly, this example demonstrates how low-cost sensors can offer preliminary or supplementary data to help inform and guide future work.

Figure 18 provides another overview of the field data. In this plot, each hour of the day is averaged for each pod using all available data - providing an indication of the diurnal patterns at each site. Again, we are seeing the nighttime increase in methane occurring at the Platteville site and to a lesser extent an increase at the Frederick site. These increases continue to be well above background and the estimated measurement error, which supports the conclusion that nighttime methane pooling was occurring in this location - a conclusion which is further supported by the observations of other researchers. Another study also conducted during the FRAPPE/DISCOVER-AQ campaign found elevated levels of benzene at the Platteville Atmospheric Observatory, occurring primarily at night. These elevated benzene concentrations were attributed to local oil and gas activity, as opposed to another source such as traffic, and the movement of the planetary boundary layer (Halliday et al., 2016). Figure 18 indicates that something similar may have been occurring with methane at the same site, likely driven by one or more sources and the fluctuations of the planetary boundary layer fluctuations. Another study using data from 2013 found the mean level of light alkanes in Platteville to be elevated 5$6 \times$ above levels in Erie and 9-15x above levels in downtown Denver (Thompson et al., 2014). This trend of elevated alkanes in Platteville and lower levels in Erie also agrees with the gradients apparent in Figs. 17 and 18 as we see the highest elevations in Platteville, moderate elevations in Frederick, and lower levels across our Erie sites. Overall, this confirms the ability of these low-cost sensors to provide unique information, in this case information regarding regional methane trends that is supported by studies that used more conventional monitoring instruments and sampling methods. 


\section{Conclusions}

A common response to the question, "How good is low-cost sensor data?" is "it depends". It depends on what question you are trying to answer, what data you intend to collect, how you would like to use the data, and what supporting measurements are available. As demonstrated by the quantification system applied to the two deployments examined in this paper, the use of low-cost sensors, certainly in the shortterm, is likely to be heavily application-dependent and sensors should be calibrated and quantified to meet the needs of a given research question and in response to the conditions of a particular deployment. As low-cost sensor systems become easier to deploy and data processing becomes more automated, these systems have tremendous potential. Their lowcost and portable nature allows for quick deployment across varied spatial scales, especially small, localized scales. Sensor data can already highlight potential "hotspots", which could lead to better allocation of resources or the detection of potential air quality issues sooner. When used in this context, the sensor system described herein can provide a useful estimate of methane concentrations that may serve as preliminary or supplementary data. In Los Angeles, we were able to provide a methane prediction despite the complexity of sources and this methane signal has the potential to provide some insight into what is happening at the neighborhood level, although special attention will need to be paid to likely confounders and cross sensitivities. In Colorado, we were able to generate a dataset that can be examined on various temporal and spatial scales as well as data able to characterize regional trends that concur with the observations of other researchers. While more research into cross sensitivities and other deployment issues is certainly necessary, this sensor system currently provides a powerful tool for understanding methane in communities near sources. Furthermore, this is a tool that is complementary to conventional monitoring methods.

Code and data availability. All sensor data (including final datasets and raw sensor data) and MATLAB code used to process the data are available through the corresponding author; please contact for access. All reference data used for analysis of the Colorado deployment were provided courtesy of the NATIVE Trailer team (Penn State University) and are available in the official DISCOVER-AQ database: https: //www-air.larc.nasa.gov/missions/discover-aq/discover-aq.html

(DISCOVER-AQ, 2015). Additional data for Los Angles analysis provided courtesy of the South Coast Air Quality Management District (note these data have not passed through the normal review process and are therefore not quality-assured, and they are thus unofficial data). 
Appendix A: Inter-sensor variability
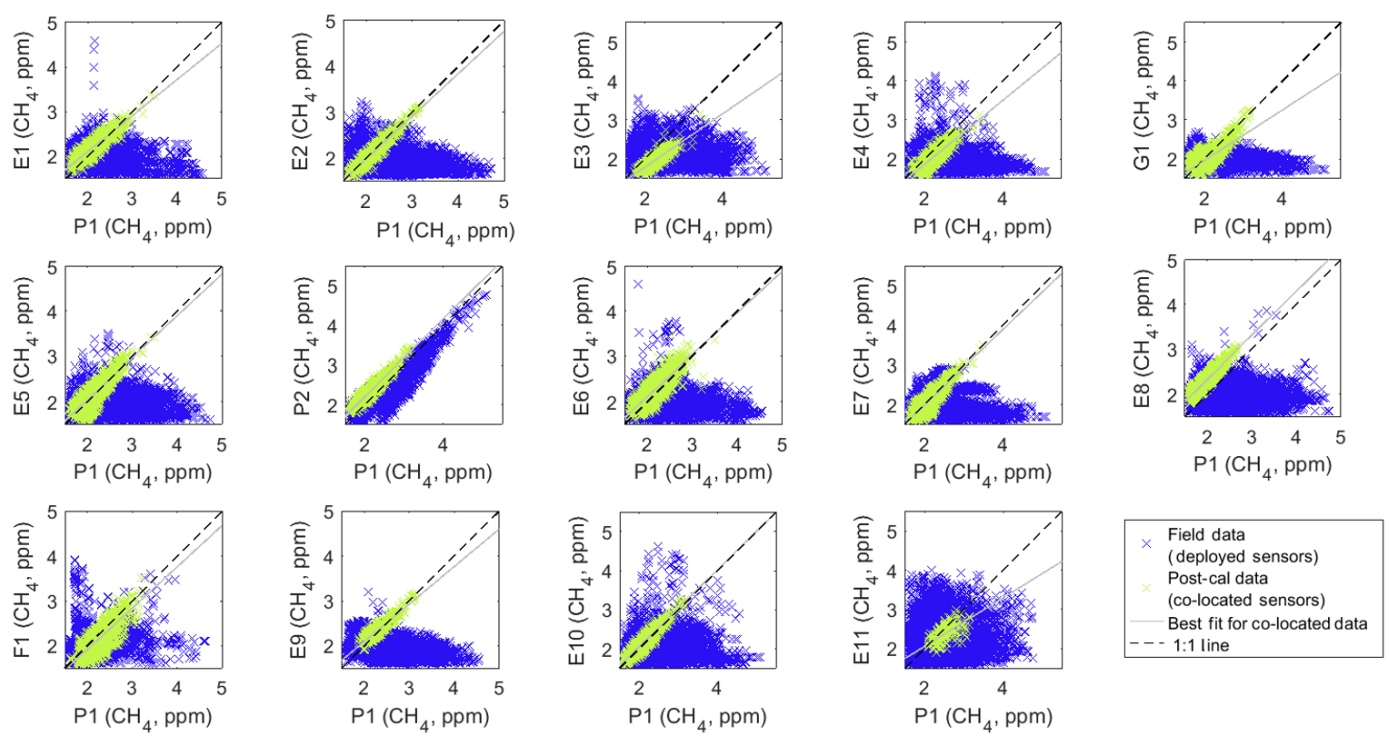

Figure A1. Scatter plots of P1 versus every other Y-Pod including both co-located data (in green) and deployed data (in blue).

Table A1. Statistics for Colorado data converted using the universal model method, including data for each individual Y-Pod and statistics for each Y-Pod versus Y-Pod P1.

\begin{tabular}{lrrrrr}
\hline & \multicolumn{2}{c}{ Co-located } & & \multicolumn{2}{c}{ Deployed } \\
\cline { 2 - 3 } \cline { 5 - 6 } & $R$ & RMSE & & $R$ & RMSE \\
\hline E1 & 0.914 & 0.117 & & -0.159 & 0.581 \\
E2 & 0.940 & 0.084 & & -0.095 & 0.594 \\
E3 & 0.909 & 0.284 & & 0.168 & 0.619 \\
E4 & 0.863 & 0.201 & & 0.050 & 0.591 \\
G1 & 0.737 & 0.200 & & -0.179 & 0.565 \\
E5 & 0.849 & 0.132 & & 0.054 & 0.529 \\
P2 & 0.961 & 0.210 & & 0.904 & 0.241 \\
E6 & 0.847 & 0.166 & & -0.061 & 0.535 \\
E7 & 0.864 & 0.124 & & -0.067 & 0.572 \\
E8 & 0.931 & 0.336 & & -0.186 & 0.599 \\
F1 & 0.819 & 0.182 & & 0.221 & 0.550 \\
E9 & 0.931 & 0.095 & & -0.454 & 0.655 \\
E10 & 0.929 & 0.107 & & 0.053 & 0.585 \\
E11 & 0.624 & 0.208 & & 0.104 & 0.571 \\
\hline Average & 0.866 & 0.175 & & 0.025 & 0.556 \\
SD & 0.092 & 0.073 & & 0.306 & 0.096 \\
\hline
\end{tabular}


Appendix B: Sensor data underestimates and methane variability

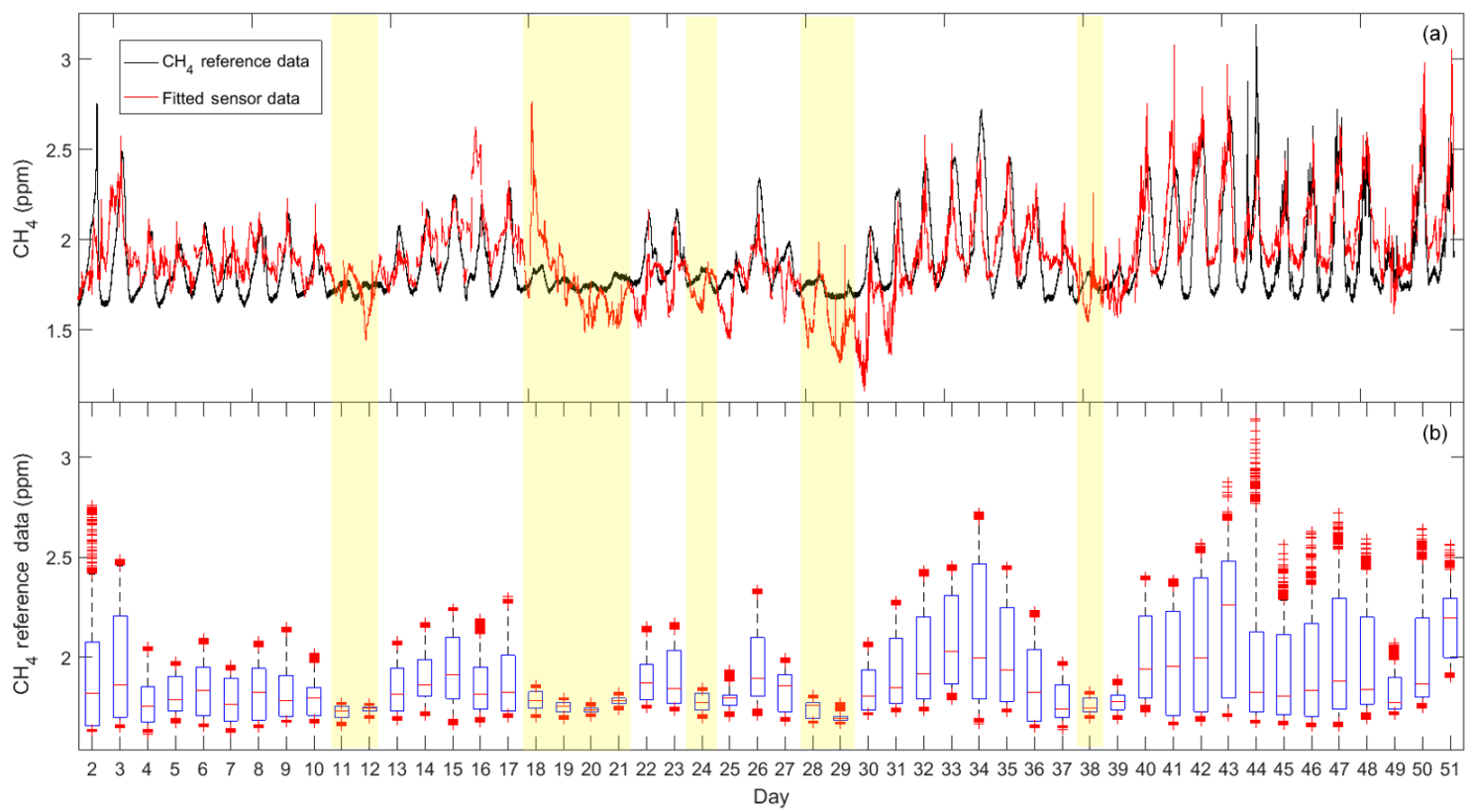

Figure B1. Panel (a) includes time series of methane reference data and fitted sensor data. Panel (b) includes the methane data for the Validation 2 dataset binned by days. The yellow segments highlight periods when underestimations below atmospheric background were removed, which coincide with days where the dynamic range is less than the expected uncertainty (RMSE is $0.18 \mathrm{ppm}$ ). 
Author contributions. ACO led the deployments in both locations with help from JC and $\mathrm{HH}$ in Colorado and help from JJ in Los Angeles. ACO, MH, JC, RP, and JO all contributed to work quantifying low-cost sensors for methane. ACO organized this manuscript with assistance and feedback from all authors.

Competing interests. The authors declare that they have no conflict of interest.

Acknowledgements. Funding provided through the MetaSense Project (NSF Grant CNS-1446912), the AirWaterGas Project (NSF-SRN CBET: 1240584), and the DISCOVER-AQ Project (NASA). Thank you to all project partners during the DISCOVERAQ/FRAPPE campaigns (NCAR, NOAA, CDPHE, US EPA), all project partners in Los Angeles at the University of Southern California Keck School of Medicine, Redeemer Community Partnership (Nicole Wong), Sandy Navarro, William Flores, Esperanza Community Housing, and Occidental College. Additional thanks to all research and regulatory partners who assisted with site access and reference data: the NATIVE trailer team, Colorado Department of Public Health and the Environment, and South Coast Air Quality Management District. Thanks to Christine Wiedinmyer (CIRES) for the deployment maps included in this paper (Sect. 2.2). Thanks to all monitor site hosts in Colorado and Los Angeles, and current and former members of the Hannigan Research Lab, especially Nicholas Masson and Drew Meyers for their work on the U-Pod/Y-Pod hardware and software, and Evan Coffey and Kira Sadighi for their assistance with the deployment in LA.

Edited by: Dwayne Heard

Reviewed by: two anonymous referees

\section{References}

Allen, D. T.: Methane emissions from natural gas production and use: reconciling bottom-up and top-down measurements, Curr. Opin. Chem. Eng., 5, 78-83, https://doi.org/10.1016/j.coche.2014.05.004, 2014.

Adgate, J. L., Goldstein, B. D., and McKenzie, L. M.: Potential public health hazards, exposures and health effects from unconventional natural gas development, Environ. Sci. Technol., 48, 8307-8320, https://doi.org/10.1021/es404621d, 2014.

Arfire, A., Marjovi, A., and Martinoli, A.: Mitigating slow dynamics of low-cost chemical sensors for mobile air quality monitoring sensor networks. ESWN '16 Proceedings of the 2016 International Conference on Embedded Wireless Systems and Networks, Conference Proceedings, 159-167, ISBN: 978-09949886-0-7, 2016.

Bamberger, I., Stieger, J., Buchmann, N., and Eugster, W.: Spatial variability of methane: attributing atmospheric concentrations to emissions, Environ. Pollut., 190, 65-74, https://doi.org/10.1016/j.envpol.2014.03.028, 2014.

Biaggi-Labiosa, A., Sola, F., Lebron-Colon, M., Evans, L. J., Xu, J. C., Hunter, G., Berger, G. M., and Gonzalez, J. M.: A novel methane sensor based on porous $\mathrm{SnO} 2$ nanorods: room tem- perature to high temperature detection, Nanotechnology, 23, 45, https://doi.org/10.1088/0957-4484/23/45/455501, 2012.

Boulder County: Past review of oil and gas development regulations, available at: https://www.bouldercounty.org/ property-and-land/land-use/planning/oil-gas-development/ history/, last access: 8 November 2017.

Casey J. G., Ortega, J., Coffey, E., and Hannigan, M.: Low-cost measurement techniques to characterize the influence of home heating fuel on carbon monoxide in Navajo homes, Sci. Total Environ., 625, 608-618, https://doi.org/10.1016/j.scitotenv.2017.12.312, 2018.

Cheadle, L., Deanes, L., Sadighi, K., Casey, J. G., Collier-Oxandale, A., and Hannigan, M.: Quantifying neighborhood-scale spatial variations of ozone at open space and urban sites in Boulder, Colorado using low-cost sensor technology, Sensors, 17, 9 , https://doi.org/10.3390/s17092072, 2017.

Clements, A., Griswold, W., RS, A., Johnston, J. E., Herting, M. M., Thorson, J., Collier-Oxandale, A., and Hannigan, M.: Low-cost air quality monitoring tools: from research to practice (a workshop summary), Sensors, 17, 2478, https://doi.org/10.3390/s17112478, 2017.

Collier, A., Knight, D., Hafich, K., Hannigan, M., Polmear, M., and Graves, B.: On the development and implementation of a projectbased learning curriculum for air quality in K-12 schools, 2015 IEEE: Frontiers in Education Conference (FIE), Conference Proceedings, https://doi.org/10.1109/FIE.2015.7344246, 2015.

Colorado Oil and Gas Conservation Commission (COGCC), Wells, data layer, available at: http://cogcc.state.co.us/documents/data/ downloads/gis/WELLS_SHP.ZIP (last access: 4 October 2017), 2015.

Colorado Oil and Gas Conservation Commission (COGCC): Online GIS Tool, available at: https://cogccmap.state.co.us/cogcc_gis_ online/, last access: 4 October 2017.

Cross, E. S., Williams, L. R., Lewis, D. K., Magoon, G. R., Onasch, T. B., Kaminsky, M. L., Worsnop, D. R., and Jayne, J. T.: Use of electrochemical sensors for measurement of air pollution: correcting interference response and validating measurements, Atmos. Meas. Tech., 10, 3575-3588, https://doi.org/10.5194/amt10-3575-2017, 2017.

Davis K. J., Deng A., Lauvaux T., Miles N. L., Richardson S. J., Sarmiento D. P., Kevin R., Gurney, R., Hardesty, M., Bonin, T. A., Brewer, W. A., Lamb, B. K., Shepson, P. B., Harvey, R. M., Cambaliza, M. O., Sweeney, C., Turnbull, J. C., Whetstone, J., and Karion, A.: The Indianapolis flux experiment (INFLUX): a test-bed for developing urban greenhouse gas emission measurements, Elem. Sci. Anth. 5, 21, https://doi.org/10.1525/elementa.188, 2017.

De Vito, S., Massera, E., Piga, M., Martinotto, L., and Di Francia, G.: On field calibration of an electronic nose for benzene estimation in an urban pollution monitoring scenario, Sensor. Actuat. BChem., 129, 750-57, https://doi.org/10.1016/j.snb.2007.09.060, 2008.

DISCOVER-AQ: Database, https://doi.org/10.5067/Aircraft/DISCOVERAQ/Aerosol-TraceGas, 2015.

Etheridge, D. M., Steele, L. P., Francey, R. J., and Langenfelds, R. L.: Atmospheric methane between 1000 A.D. and present: evidence of anthropogenic emissions and climatic variability, J. Geophys. Res-Atmos., 103, 15979-15993, https://doi.org/10.1029/98JD00923, 1998. 
Eugster, W. and Kling, G. W.: Performance of a low-cost methane sensor for ambient concentration measurements in preliminary studies, Atmos. Meas. Tech., 5, 1925-1934, https://doi.org/10.5194/amt-5-1925-2012, 2012.

Fang, Y., Naik, V., Horowitz, L. W., and Mauzerall, D. L.: Air pollution and associated human mortality: the role of air pollutant emissions, climate change and methane concentration increases from the preindustrial period to present, Atmos. Chem. Phys., 13, 1377-1394, https://doi.org/10.5194/acp-13-1377-2013, 2013.

Figaro: TGS 2600 - for the detection of air contaminants, On-line product data sheet, available at: http://www.figarosensor.com/ products/2600pdf.pdf (last access: 4 October 2017), 2005.

Fiore, A. M., West, J. J., Horowitz, L. W., Naik, V., and Schwarzkopf, M. D.: Characterizing the tropospheric ozone response to methane emission controls and the benefits to climate and air quality, J. Geophys. Res., 113, 2156-2202, https://doi.org/10.1029/2007JD009162, 2008.

Hagler, G. S. W., Yelverton T. L. B., Vedantham, R., Hansen, A. D. A., and Turner, J. R.: Post-processing method to reduce noise while preserving high time resolution in aethalometer realtime black carbon data, Aerosol Air Qual. Res., 11, 539-546, https://doi.org/10.4209/aaqr.2011.05.0055, 2011.

Halliday, H. S., Thompson, A. M., Wisthaler, A., Blake, D., Hornbrook, R. S., Mikoviny, T., Muller, M., Eicher, P., Apel, E. C., and Hills, A. J.: Atmospheric benzene observations from oil and gas production in the Denver Julesburg basin in July and August 2014, J. Geophys. Res.-Atmos., 121, 11055-11074, https://doi.org/10.1002/2016JD025327, 2016.

Heimann, I., Bright, V. B., McLeod, M. W., Mead, M. I., Popoola, O. A. M., Stewart, G. B., and Jones, R. L.: Source attribution of air pollution by spatial scale separation using high spatial density networks of low cost air quality sensors, Atmos. Environ., 113, 10-19, https://doi.org/10.1016/j.atmosenv.2015.04.057, 2015.

Helmig, D., Thompson, C. R., Evans, J., Boylan, P., Hueber, J., and Park, J. H.: Highly elevated atmospheric levels of volatile organic compounds in the uintah basin, Utah, Environ. Sci. Technol., 48, 4707-4715, https://doi.org/10.1021/es405046r, 2014.

Huyberechts, G., Szeco, P., Roggen, J., and Licznerski, B. W.: Simultaneous quantification of carbon monoxide and methane in humid air using a sensor array and an artificial neural network, Sensor. Actuat. B-Chem., 45, 123-30 https://doi.org/10.1016/S0925-4005(97)00283-9, 1997.

Intergovernmental Panel on Climate Change (IPCC): Climate Change 2014 Synthesis Report, available at: https://www.ipcc. ch/pdf/assessment-report/ar5/syr/SYR_AR5_FINAL_full.pdf (last access: 4 October 2017), ISBN: 978-92-9169-143-2, 2015.

Karion, A., Sweeney, C., Pétron, G., Frost, G., Hardesty, R. M., Kofler, J., Miller, B. R., Newberger, T., Wolter, S., Banta, R., Brewer, A., Dlugokencky, E., Lang, P., Montzka, S. A., Schnell, R. S., Tans, P., Trainer, M., Zamora, R., and Conley, S.: Methane emissions estimate from airborne measurements over a western United States natural gas field, Geophys. Res. Lett., 40, 43934397, https://doi.org/10.1002/grl.50811, 2013.

Kim, J., Shusterman, A. A., Lieschke, K. J., Newman, C., and Cohen, R. C.: The BErkeley Atmospheric $\mathrm{CO}_{2} \mathrm{Ob}-$ servation Network: field calibration and evaluation of lowcost air quality sensors, Atmos. Meas. Tech., 11, 1937-1946, https://doi.org/10.5194/amt-11-1937-2018, 2018.
Kort, E. A., Frankenberg, C., Costigan, K. R., Lindenmaier, R., Dubey, M. K., and Wunch, D.: Four corners: the largest US methane anomaly viewed from space, Geophys. Res. Lett., 41, 6898-6903, https://doi.org/10.1002/2014GL061503, 2014.

Lewis, A. C., Lee, J., Edwards, P. M., Shaw, M. D., Evans, M. J., Moller, S. J., Smith, K. R., Buckley, J. W., Ellis, M., Gillot, S. R., and White, A.: Evaluating the performance of low cost chemical sensors for air pollution research, Faraday Discuss., 189, 85-103, https://doi.org/10.1039/C5FD00201J, 2016.

Masson, N., Piedrahita, R., and Hannigan, M.: Approach for quantification of metal oxide type semiconductor gas sensors used for ambient air quality monitoring, Sensor. Actuat. B-Chem., 208, 339-345, https://doi.org/10.1016/j.snb.2014.11.032, 2015a.

Masson, N., Piedrahita, R., and Hannigan, M.: Quantification method for electrolytic sensors in long-term monitoring of ambient air quality, Sensors, 15, 27283-27302, https://doi.org/10.3390/s151027283, 2015b.

Mead, M. I., Popoola, O. A. M., Stewart, G. B., Landshoff, P., Calleja, M., Hayes, M., Baldovi, J. J., McLeod, M. W., Hodgson, T. F., Dicks, J., Lewis, A., Cohen, J., Baron, R., Saffell, J. R., and Jones, R. L.: The use of electrochemical sensors for monitoring urban air quality in lowcost, high-density networks, Atmos. Environ., 70, 186-203, https://doi.org/10.1016/j.atmosenv.2012.11.060, 2013.

Miller, S. M., Wofsy, S. C., Michalak, A. M., Kort, E. A., Andrews, A. E., Biraud, S. C., Dlugokencky, E. J., Eluszkiewicz, J., Fischer, M. L., Janssens-Maenhout, G., Miller, B. R., Miller, J. B., Montzka, S. A., Nehrkorn, T., and Sweeney, C.: Anthropogenic emissions of methane in the United States, P. Natl. Acad. Sci. USA, 110, 20018-20022, https://doi.org/10.1073/pnas.1314392110, 2013.

Mobile Sensing Technology: U-Pod open-source construction and parts information, available at: http://mobilesensingtechnology. com/, last access: 4 October 2017.

Mocon, Inc - Baseline: Series 9000 Total Hydrocarbon Analyzer, available at: www.baseline-mocon.com (last access: 7 May 2018), 2017.

Moltchanov, S., Levy, I., Etzion, Y., Lerner, U., Broday, D. M., and Fishbain, B.: On the feasibility of measuring urban air pollution by wireless distributed sensor networks, Sci. Total Environ., 502, 537-547, https://doi.org/10.1016/j.scitotenv.2014.09.059, 2015.

Moore, C. W., Zielinska, B., Petron, G., and Jackson, R. B.: Air impacts of increased natural gas acquisition, processing, and use: a critical review, Environ. Sci. Technol., 48, 8349-8359, https://doi.org/10.1021/es4053472, 2014.

Nam, E. K., Jensen, T. E., and Wallington, T. J.: Methane Emissions from Vehicles, Environ. Sci. Technol., 38, 2005-2010, https://doi.org/10.1021/es034837g, 2004.

National Oceanic and Atmospheric Association (NOAA): Global Greenhouse Gas Reference Network: Trends in Atmospheric Methane, available at: https://www.esrl.noaa.gov/gmd/ccgg/ trends_ch4/\#global_data, last access: 4 October 2017.

Peischl, J., Ryerson T. B., Brioude, J., Aikin, K. C., Andrews, A. E., Atlas, E., Blake, D., Daube, B.C., De Gouw, J. A., Dlugokencky, E., Frost, G. J., Gentner, D. R., Gilman, J. B., Goldstein, A. H., Harley, R. A., Holloway, J. S., Kofler, J., Kuster, W. C., Lang, P. M., Novelli, P.C., Santoni, G. W., Trainer, M., Wofsy, S. S. C., and Parrish, D. D.: Quantifying sources of methane using light 
alkanes in the Los Angeles Basin, California, J. Geophys. Res.Atmos., 118, 4974-90, https://doi.org/10.1002/jgrd.50413, 2013. Penza, M., Suriano, D., Cassano, G., Pfister, V., Amodio, M., Trizio, L., Brattoli, M., and De Gennaro, G.: A case-study of microsensors for landfill air-pollution monitoring applications, Urban Climate, 14, 351-369, https://doi.org/10.1016/j.uclim.2014.09.002, 2015.

Pétron, G., Karion, A., Sweeney, C., Miller, B. R., Montzka, S. A., Frost, G. J., Trainer, M., Tans, P., Andrews, A., Kofler, J., Helmig, D., Guenther, D., Dlugokencky, E., Lang, P., Newberger, T., Wolter, S., Hall, B., Novelli, P., Brewer, A., Conley, S., Hardesty, M., Banta, R., White, A., Noone, D., Wolfe, D., and Schnell, R.: A new look at methane and nonmethane hydrocarbon emissions from oil and natural gas operations in the Colorado Denver-Julesburg Basin, J. Geophys. Res.-Atmos., 119, 6836-6852, https://doi.org/10.1002/2013JD021272, 2014.

Picarro, Inc: Picarro G2301 CRDS Analyzer CO2 CH4 H2O Measurements in Air, available at: www.picarro.com (last access: 7 May 2018), 2015.

Pfister G., Flocke, F., Hornbrook, R., Orlando, J., Lee, S., and Schroeder, J.: Final Report: Process-Based and Regional Source Impact Analysis for FRAPPÉ and DISCOVER-AQ 2014, National Center for Atmospheric Research, available at: https:// www.colorado.gov/airquality/tech_doc_repository.aspx?action= open\&file=FRAPPE-NCAR_Final_Report_July2017.pdf, last access: 4 November 2017.

Piedrahita, R., Xiang, Y., Masson, N., Ortega, J., Collier, A., Jiang, Y., Li, K., Dick, R. P., Lv, Q., Hannigan, M., and Shang, L.: The next generation of low-cost personal air quality sensors for quantitative exposure monitoring, Atmos. Meas. Tech., 7, 3325-3336, https://doi.org/10.5194/amt-7-3325-2014, 2014.

Popa, M. E., Vollmer, M. K., Jordan, A., Brand, W. A., Pathirana, S. L., Rothe, M., and Röckmann, T.: Vehicle emissions of greenhouse gases and related tracers from a tunnel study: $\mathrm{CO}: \mathrm{CO}_{2}$, $\mathrm{N}_{2} \mathrm{O}: \mathrm{CO}_{2}, \mathrm{CH}_{4}: \mathrm{CO}_{2}, \mathrm{O}_{2}: \mathrm{CO}_{2}$ ratios, and the stable isotopes ${ }^{13} \mathrm{C}$ and ${ }^{18} \mathrm{O}$ in $\mathrm{CO}_{2}$ and $\mathrm{CO}$, Atmos. Chem. Phys., 14, 21052123, https://doi.org/10.5194/acp-14-2105-2014, 2014.

Quaranta, F., Rella, R., Siciliano, P., Capone, S., Epifani, M., Vasanelli, L., Licciullic, A., and Zoccod, A.: A novel gas sensor based on $\mathrm{SnO} 2 / \mathrm{Os}$ thin film for the detection of methane at low temperature, Sensor. Actuat. B-Chem., 58, 350-355, https://doi.org/10.1016/S0925-4005(99)00095-7, 1999.

Sadd, J. and Shamasunder, B.: Oil extraction in Los Angeles: health, land use, and environmental justice consequences, from the Drilling Down Report, by the Liberty Hill Foundation, available at: https://www.libertyhill.org/sites/libertyhillfoundation/ files/DrillingDownReport_1.pdf (last access: 4 October 2017), 2015

Sadighi, K., Coffey, E., Polidori, A., Feenstra, B., Lv, Q., Henze, D. K., and Hannigan, M.: Intra-urban spatial variability of surface ozone in Riverside, CA: viability and validation of low-cost sensors, Atmos. Meas. Tech., 11, 1777-1792, https://doi.org/10.5194/amt-11-1777-2018, 2018.

Shamasunder, B., Collier-Oxandale, A., Blickley, J., Sadd, J., Chan, M., Navarro, S., Hannigan, M., and Wong, N. J.: Communitybased health and exposure study around urban oil developments in south Los Angeles, Int. J. Environ. Res. Public Health, 15, 1, https://doi.org/10.3390/ijerph15010138, 2018.
Snyder, E. G., Watkins, T. H., Solomon, P. A., Thoma, E. D., Williams, R. W., Hagler, G. S. W., Shelow, D., Hindin D. A., Kilaru, V. J., and Preuss, P. W.: The changing paradigm of air pollution monitoring, Environ. Sci. Technol., 47, 11369-11377 https://doi.org/10.1021/es4022602, 2013.

Spinelle, L., Gerboles, M., Villani, M. G., Aleixandre, M., and Bonavitacola, F.: Field calibration of a cluster of low-cost available sensors for air quality monitoring. part A: ozone and nitrogen dioxide, Sensor. Actuat. B-Chem., 215, 249-257, https://doi.org/10.1016/j.snb.2015.03.031, 2015.

Spinelle, L., Gerboles, M., Villani, M. G., Aleixandre, M., and Bonavitacola, F.: Field calibration of a cluster of low-cost commercially available sensors for air quality monitoring. part B: NO, CO and CO2, Sensor. Actuat. B-Chem., 238, 706-715, https://doi.org/10.1016/j.snb.2016.07.036, 2017.

Subramanian, R., Williams, L. L., Vaughn, T. L., Zimmerle, D., Roscioli, J. R., Herndon, S. C., Yacovitch, T. I., Floerchinger, C., Tkacik, D. S., Mitchell, A. L., Sullivan, M. R., Dallman, T. R., and Robinson, A. L.: Methane emissions from natural gas compressor stations in the transmission and storage sector: measurements and comparisons with the EPA greenhouse gas reporting program protocol, Environ. Sci. Technol., 49, 3252-3261, https://doi.org/10.1021/es5060258, 2015.

Sun, Y. F., Liu, S. B., Meng, F. L., Liu, J. Y., Jin, Z., Kong, L. T., and Liu, J. H.: Metal oxide nanostructures and their gas sensing properties: a review, Sensors 12, 2610-2631, https://doi.org/10.3390/s120302610, 2012.

Thompson, C. R., Hueber, J., and Helmig, D.: Influence of oil and gas emissions on ambient atmospheric nonmethane hydrocarbons in residential areas of Northeastern Colorado, Elementa: Science of the Anthropocene, 3, 35, https://doi.org/10.12952/journal.elementa.000035, 2014.

United States Energy Information Administration (US EIA): Top 100 oil fields, available at: https://www.eia.gov/naturalgas/ crudeoilreserves/top100/pdf/top100.pdf (last access: 4 October 2017), 2015.

United States Energy Information Administration (US EIA): States Profiles and Energy Estimates, Colorado, available at: https: //www.eia.gov/state/analysis.php?sid=CO (last access: 4 October 2017), 2016a.

United States Energy Information Administration (US EIA): States Profiles and Energy Estimates, California, available at: https:// www.eia.gov/state/analysis.php?sid=CA (last access: 4 October 2017), 2016 b.

United States Environmental Protection Agency (US EPA): Technical Note - Reporting Negative Values for Criteria Pollutant Gaseous Monitors to AQS, available at: https://www.epa.gov/sites/production/files/2017-02/documents/ negative_values_reporting_to_aqs_10_6_16.pdf (last access: 15 April 2018), 2016.

United States Environmental Protection Agency (US EPA): Overview of greenhouse gases: methane, available at: https: //www.epa.gov/ghgemissions/overview-greenhouse-gases\# CH4reference, last access: 4 October 2017.

Van den Bossche, M., Rose, N. T., and De Wekker, S. F. J.: Potential of a low-cost gas sensor for atmospheric methane monitoring, Sensor. Actuat. B-Chem., 238, 501-509, https://doi.org/10.1016/j.snb.2016.07.092, 2017. 
Wang, C., Yin, L., Zhang, L., Xiang, D., and Gao, R.: Metal oxide gas sensors: sensitivity and influencing factors, Sensors, 10, 2088-2106, https://doi.org/10.3390/s100302088, 2010.

West, J. J., Arlene, F. M., Horowitz, L. W., and Mauzerall, D. L.: Global health benefits of mitigating ozone pollution with methane emission controls, P. Natl. Acad. Sci. USA., 103, 39883993, https://doi.org/10.1073/pnas.0600201103, 2006.

Wilcox, J., Gopstein, A. M., Arent, D., Wofsy, S., Brown, N. J., Bradley, R., and Stucky, G. D.: Methane leaks from north american natural gas systems, Science, 343, 733-735, https://doi.org/10.1126/science.1247045, 2014.

Wong, K. W., Fu, D., Pongetti, T. J., Newman, S., Kort, E. A., Duren, R., Hsu, Y.-K., Miller, C. E., Yung, Y. L., and Sander, S. P.: Mapping $\mathrm{CH}_{4}: \mathrm{CO}_{2}$ ratios in Los Angeles with CLARSFTS from Mount Wilson, California, Atmos. Chem. Phys., 15, 241-252, https://doi.org/10.5194/acp-15-241-2015, 2015.

Yacovitch T. I., Herndon, S. C., Pétron, G., Kofler, J., Lyon, D., Zahniser, M. S., and Kolb C. E.: Mobile laboratory observations of methane emissions in the barnett shale region, Environ. Sci. Technol., 49, 7889-7895, https://doi.org/10.1021/es506352j, 2015.
Zavala-araiza, D., Lyon, D. R., Alvarez, R. A., Davis, K. J., Harriss, R., Herndon, S. C., Karion, A., Kort, E. A., Lamb, B. K., Lan, X. Marchese, A. J., Pacala, S. W., Robinson A. L., Shepson, P. B., Sweeny, C., Talbot, R., TownsendSmall, A., Yacovitch, T. I., Zimmerle D. J., and Hamburg, S. P.: Reconciling divergent estimates of oil and gas methane emissions, P. Natl. Acad. Sci. USA., 112, 15597-15602, https://doi.org/10.1073/pnas.1522126112, 2015.

Zimmerman, N., Presto, A. A., Kumar, S. P. N., Gu, J., Hauryliuk, A., Robinson, E. S., Robinson, A. L., and R. Subramanian: A machine learning calibration model using random forests to improve sensor performance for lower-cost air quality monitoring, Atmos. Meas. Tech., 11, 291-313, https://doi.org/10.5194/amt11-291-2018, 2018.

Zhang, Z., Tong, J., Chen, D., and Yu-bin Lan, Y.: Electronic nose with an air sensor matrix for detecting beef freshness, J. Bionic Eng., 5, 67-73, https://doi.org/10.1016/S1672-6529(08)60008-6, 2008. 